Portland State University

PDXScholar

Summer 10-1-2013

\title{
Evidence Supporting Treatment Practice Based Delineation of Stormwater Runoff Zones
}

Jacob J. Gorski

Portland State University

Follow this and additional works at: https://pdxscholar.library.pdx.edu/open_access_etds

Part of the Environmental Engineering Commons, and the Urban Studies and Planning Commons Let us know how access to this document benefits you.

\section{Recommended Citation}

Gorski, Jacob J., "Evidence Supporting Treatment Practice Based Delineation of Stormwater Runoff Zones" (2013). Dissertations and Theses. Paper 1423.

https://doi.org/10.15760/etd.1422

This Thesis is brought to you for free and open access. It has been accepted for inclusion in Dissertations and Theses by an authorized administrator of PDXScholar. Please contact us if we can make this document more accessible: pdxscholar@pdx.edu. 
Evidence Supporting Treatment Practice Based Delineation of Stormwater Runoff Zones

by

Jacob J. Gorski

A thesis submitted in partial fulfillment of the requirements for the degree of

Master of Science

in

Civil \& Environmental Engineering

Thesis Committee:

William Fish, Chair

Timothy Anderson

Scott Wells

Portland State University

2013 


\section{Abstract}

Particles mobilized by stormwater negatively affect receiving surface waters. Stormwater best management practices (BMPs) can reduce solids along with associated pollutants in runoff but engineers and environmental managers have been long vexed by the problem of choosing the optimal BMP for a given situation. A common BMP process for solids removal is sedimentation. This thesis addresses the question of whether the effectiveness (and thus choice) of a sedimentation device can be estimated (and thus optimized) from the particle size properties of runoff, which, in turn, could be associated with specific runoff zones or land uses. Presented here is a series of experiments to determine the solids-removal capabilities of a manufactured oil-water separator that also removes solids via sedimentation. A statistical model developed from the experimental data shows that, under normal operating conditions, influent particle size can be used to accurately estimate effluent total suspended solids (TSS) for BMPs of this type. Relationships between particle size and particle-bound metal concentrations for $\mathrm{Cu}, \mathrm{Zn}$ and $\mathrm{Pb}$ were then obtained from the literature and incorporated into the model to allow estimates of metal removal efficiencies based on TSS and PSD. The model can be used with an arbitrary particle size distribution (PSD); this allows effluent quality predictions to be made considering that particle sizes 
entering stormwater BMPs could vary due to anthropogenic, hydraulic or hydrologic factors. To place these experimental and modeling results in the context of an urban environment, samples of deposited stormwater solids were collected from residential areas, commercial areas and an industrial zone in Portland, Oregon, and the PSD of each sample was determined using light obstruction particle sizing. PSDs ranging over sizes from $3 \mu \mathrm{m}$ to $200 \mu \mathrm{m}$ vary among these locations. Areas with high anthropogenic impact were found to have PSDs skewed toward the smallest particle sizes. The statistical model developed here was then used to show that the effluent quality of the BMP tested would differ depending on the locations where solids were collected. The evidence presented in this thesis thus indicates that device performance will correlate with geographic locations or land use zone and validates further investigation into delineating the City of Portland's characteristic runoff zones and using the runoff characteristics of each zone to map it to the most desirable treatment practices. 


\section{Table of Contents}

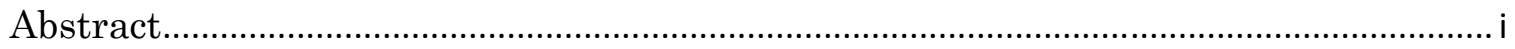

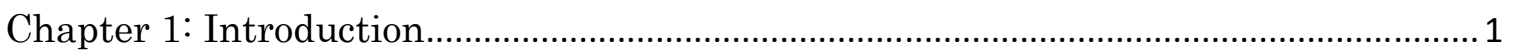

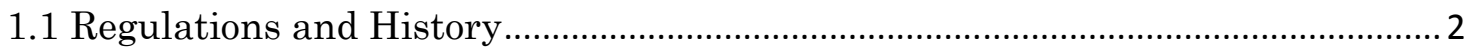

Chapter 2: Choosing Best Management Practices for Stormwater Control................... 6

2.1 Best Management Practices ..................................................................................... 6

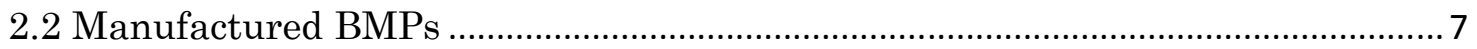

2.3 Effluent Quality of Manufactured Devices............................................................ 8

2.4 Optimal Choice of a BMP or Manufactured Device ............................................... 11

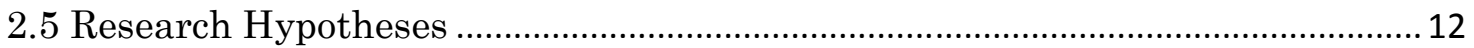

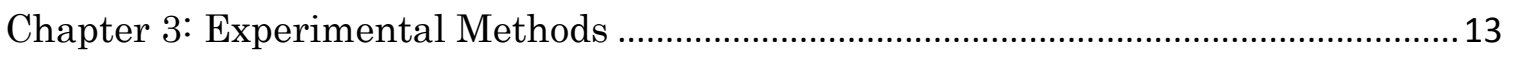

3.1Background on Experimental Testing of Manufactured BMPs............................13

3.2 Simulated Stormwater Experiment...................................................................... 13

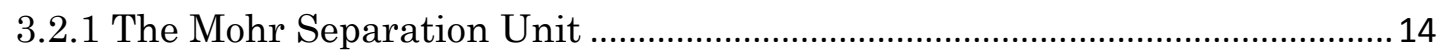

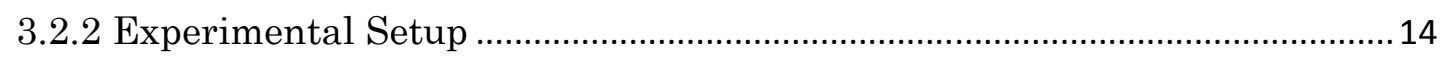

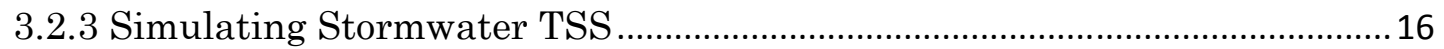

3.2.4 Sample Collection and TSS Analysis Method …........................................... 17

3.3 Particle Size Distribution Testing.......................................................................... 19

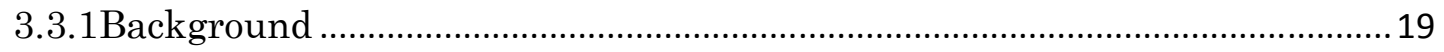

3.3.2 The HIAC +9703 Particle Counter ……......................................................... 20

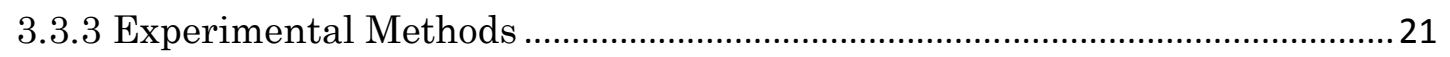

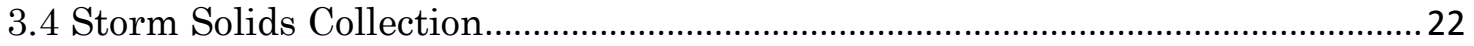

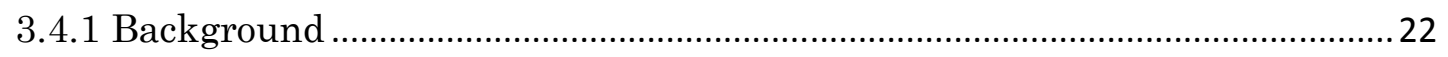

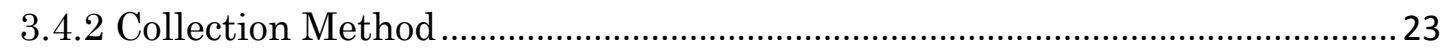

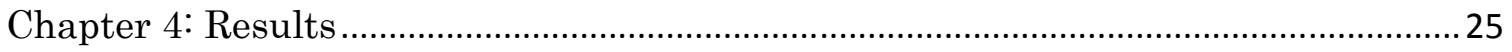

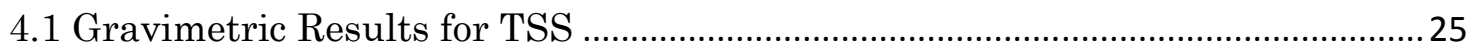

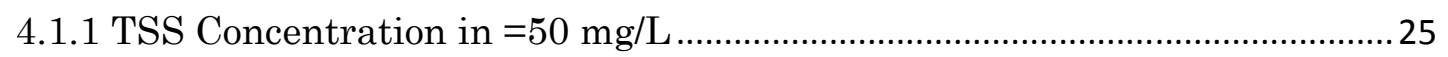

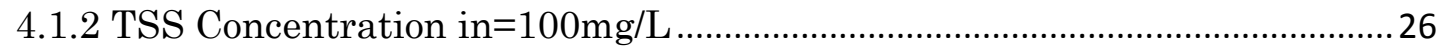

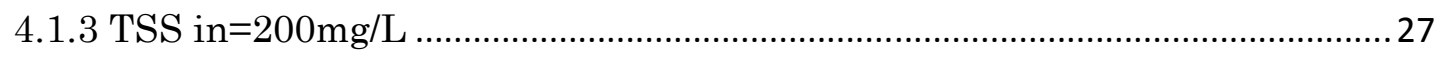




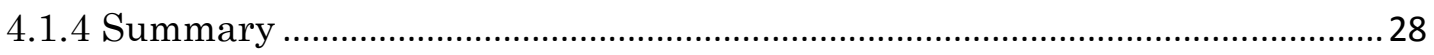

4.2 Particle Size Distribution....................................................................................... 30

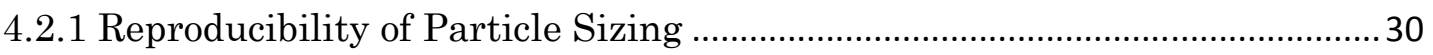

4.2.2 PSD of Simulated Storm ……………………………………………….......

4.2.3 PSD of Collected Stormwater Particulates ..........................................................35

4.2.4 Previous Particle Sizing Studies in Portland, Oregon ......................................37

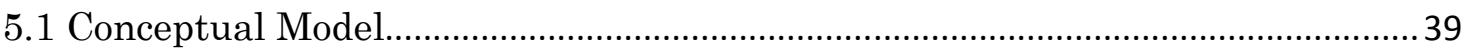

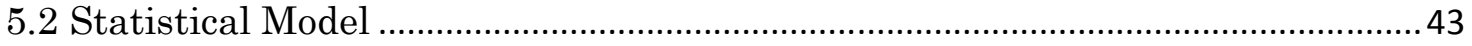

5.2.1 Selection of Statistical Model....................................................................... 46

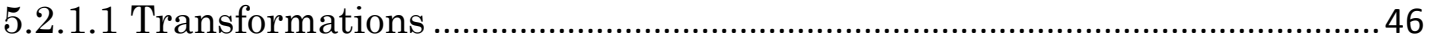

5.2.1.2 Non-Parametric Regression ....................................................................... 47

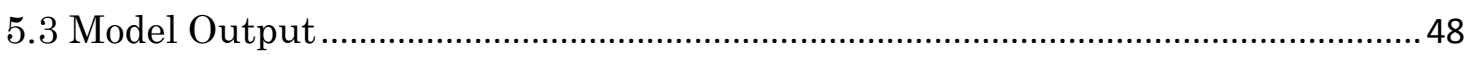

5.3.1 Statistical Significance of Model ................................................................... 48

5.3.2 Model Output Using PSD of Collected Stormwater Particulate .....................51

5.4 A Model to Predict Sediment Bound Heavy Metal Concentrations Based on

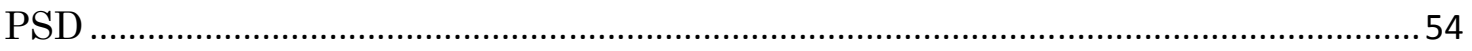

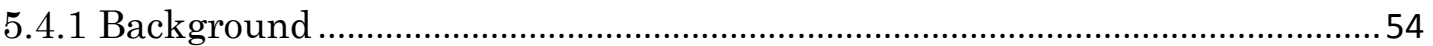

5.4.2 Statistical Summary of Particulate Bound Metals by Particle Size ............ 58

5.4.3 Using Particle Size and Associated Pollutant Concentrations to

Demonstrate Importance of Site Specific Runoff Characteristics ...........................60

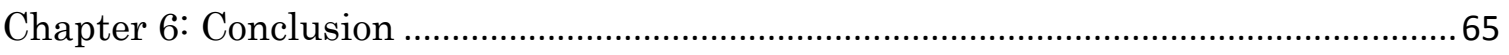

6.1 Ideas for Future Research....................................................................................66

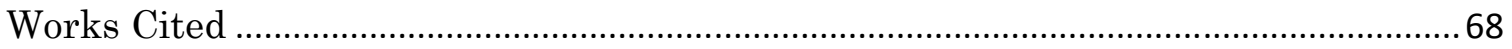




\section{List of Tables}

Table 1:Methods used, and details on methods for sizing particles in stormwater adapted from Grant et al. (2003)

Table 2: Sample sediment deposition locations, land use type and traffic intensity

Table 3: Statistical summary of gravimetric testing at all operational conditions

Table 4: $\mathrm{P}$ values for two-tailed $\mathrm{T}$ tests comparing 50 and $100 \mathrm{mg} / \mathrm{L}$ influent concentrations to the $200 \mathrm{mg} / \mathrm{L}$ influent concentration

Table 5: Difference proportion mean and variance for 10 duplicate samples and mean count numbers

Table 6: Particle mass reduction from summation of assumed spherical particles counts into and out of unit and mass reduction of particles determined using gravimetric method

Table 7: Critical settling velocities and corresponding particle sizes

Table 8: Selected size bins for particle counts used

Table 9: Parameters generated from non-parametric regression

Table 10: Predicted mass reduction of particulate collected

Table 11: Particle bound heavy metal concentrations by particle size adapted from (Wilson et al. 2007)

Table 12: Binding phases of particulate bound metals measured in sediment cores taken from the Ell-Ren River in Southern Taiwan adapted from(Yu et al. 2001)

Table 13: Statistical summary for particulate metal concentration observed in stormwater particles at a variety of locations exclusively considering particle size 


\section{List of Figures}

Figure 1: TSS influent and effluent concentrations for a variety of BMPs

Figure 2: Paired influent/effluent event mean concentrations of TSS for manufactured devices with a primary treatment of processes of density/gravity/inertial separation and sedimentation

Figure 3: Photograph of simulated stormwater experiment

Figure 4: PSD of SCS as determined using the HIAC +9750 particle counter

Figure 5: Todd Gunter, of the BES, collecting stormwater solids from

sedimentation manhole using the described piping system

Figure 6: Box plots for \%TSS removal. Influent TSS=50 mg/L

Figure 7: Box plots for \% TSS removal. Influent TSS=100 mg/L

Figure 8: Box plots for \% TSS removal. Influent TSS=200 mg/L

Figure 9: PSD of SCS as at determined using the HIAC +9750

Figure 10: Removal of particle size by mass and percent for simulated storm solids

Figure 11: Particle size distributions of collected storm solids

Figure 12: Conceptual and statistical models for removal fraction of particle sizes at 3 operational conditions

Figure 13: Occurrences of percent removal by count and corresponding density plot with particle measurements taken at log spacing intervals from $3.5 \mu \mathrm{m}$ to $90 \mu \mathrm{m}$

Figure 14: Occurrences of non-removal by particle diameter

Figure 15: Residuals comparing model A to measured values

Figure 16: Particle bound copper, lead and zinc concentrations $(\mathrm{mg} / \mathrm{kg})$ by mean particle size based on data from table 9

Figure 17: Estimated influent and effluent particulate bound $\mathrm{Zn}, \mathrm{Pb}$ and $\mathrm{Cu}$ for two different PSDs 


\section{Chapter 1: Introduction}

When precipitation occurs in undeveloped areas a number of abstractions catch and absorb that precipitation. Abstractions include plants and trees, which catch a portion of the water, pervious soils that infiltrate stormwater until saturated and natural changes in topography where stormwater accumulates. During more intense, longer storm events the abstraction limit in a watershed can be reached and runoff occurs. In the process of developing areas for cities, towns, industrial sites and transportation the watershed characteristics of that area are changed and the quantity of abstraction in the developed area is reduced. Pervious soils are replaced with impervious surfaces and plants that abstract, absorb and release moisture through evapotranspiration are removed. As a result a significantly larger quantity of surface runoff is generated in these areas.

There are a number of methods used to manage the quantity of runoff. Two popular options are the combined sewer system and the separate sewer system. The combined sewer system conveys stormwater runoff and sanitary sewage to a wastewater treatment plant. After treatment water is released into a receiving body and the quality of the effluent is monitored to comply with water quality regulations in general, or for water quality regulations at a particular receiving body of water. The separate sewer system, also known as the municipal separate storm sewer system (MS4) conveys stormwater 
separate from sanitary waste. The MS4 generally discharges stormwater to a receiving body of water through a system of outfalls while sanitary sewage is conveyed to a wastewater treatment plant. Because stormwater picks up and transports pollutants deposited in urban areas, and is then discharged to a receiving body or treated along with sanitary waste it is necessary to reduce pollutants and/or reduce quantity of runoff for water quality and economic reasons. Within stormwater management methods that reduce runoff volume and or runoff pollution are called best management practices (BMP).

\subsection{Regulations and History}

Early examples of stormwater management and conveyance systems can be found throughout history: the Incas utilized decentralized disconnected infiltration systems at Machu Picchu (Wright et al. 1999) similar to modern low impact development (LID) BMPs and the ancient cities of Ur and Babylon had effective drainage systems for stormwater (Burian and Edwards 2004). The first urban drainage systems in North America were constructed in New England during the colonial era.

Many early civilizations had methods to manage stormwater and sanitary waste quantity. However, these civilizations were understandably unaware of water quality criteria such as waterborne disease which was, and remains in some parts of the world, a serious problem. The correlation between disease and contaminated water was made in 1854 (Frerichs n.d.) by Dr. John Snow 
and marked a turning point in both engineering and science. Snow's work was not immediately well received by his peers despite the fact that Snow's study showed overwhelming scientific evidence. For a while after Snow's publication it was still believed that diseases, like cholera, were spread by miasma, a poisonous vapor which entered the body through the nose or mouth that was produced by warm air, moisture and decaying animal and vegetable matter (Rees 1996).

Despite not being completely aware of the dangers associated with wastewater, the first modern day centralized water-carriage sewer system was constructed in Hamburg Germany in 1842 (Seeger 1999). The successful implementation of this centralized system paved the way for other sewer systems and by the late 1850 s combined systems were being constructed in Chicago and Brooklyn. This installation of sewer systems throughout American cities and towns marked a turning point in how stormwater and sanitary sewage was managed. Imaginably, sewers increased the quality of life for urban residents, however the sewers also made it easier for industry to dispose of waste chemicals and environmental regulation did not yet exist.

In 1899 the United States passed its first federal environmental regulation to protect waterways, the Refuse Act (RA). This early legislation made unauthorized depositing, discharging and all other means of evacuating 
waste and garbage material into navigable waters and tributaries of navigable waters illegal. Compared to modern environmental regulations the RA was simple and unfortunately ineffective. Advances in industry coupled by the economic boom the United States experienced post World War II resulted in a new type of pollution problem. Sewage treatment plants were common practice by this point in time; however the plasticizers, inorganic pesticides and legacy pollutants that were being dumped into water sources had different effects than waterborne disease. Not only did this pollution affect human health, but it harmed aquatic ecosystems and it bioaccumulated. In response to this new pollution the federal government enacted the Water Pollution Control Act in 1948. The EPA did not yet exist so water quality standards, effluent limitations and the enforcement that would come with subsequent environmental legislation was not yet present.

Amendments to the Water Pollution Control Act made in 1956 brought about minimal enforcement of interstate pollution and provided a percentage of Federal dollars for the construction of waste water treatment plants.

In 1965 the Water Quality Act (WQA) was enacted, establishing quality standards. The WQA was difficult to implement as it required a link between individual polluters and water quality. Industrial pollution continued and numerous water quality incidents sparked demand for more effective 
regulations. In 1972 the Clean Water Act (CWA) was passed. The CWA intended to eliminate contaminated effluent discharge into navigable waters by 1985 by focusing on using technology. Nonpoint pollution was still considered a local responsibility, but federal grants were provided for nonpoint pollution programs and the National Pollutant Discharge Elimination System (NPDES) was introduced. Further amendments to the CWA came about in 1977 and 1987.

The CWA improved the Nation's waters dramatically. However, the National Water Quality Inventory of 2000 showed that 40 percent of the surveyed water bodies did not meet water quality standards, of those 13 percent of impaired rivers, 18 percent of impaired lakes and 32 percent of impaired estuaries were affected by urban/suburban stormwater runoff (The United States Environmental Protection Agency, 2005). Prior to this, in 1990 Phase I of the EPA's stormwater program was enacted and in 1999 Phase II of the stormwater program was published further expanding on the requirements for stormwater best management practices. The stormwater program was designed to reduce negative impacts to water bodies caused by certain unregulated stormwater discharges. Increasing regulations and demand for sustainable infrastructure drive the technological, engineering and planning innovations that keep the field of stormwater management changing. 
Chapter 2: Choosing Best Management Practices for Stormwater Control

\subsection{Best Management Practices}

There are a variety of BMP types that can be used for different purposes.

Broadly BMPs can be categorized as structural, or non-structural. Nonstructural BMPs include educational programs, maintenance requirements such as sweeping and specifications on where certain items may be stored. Structural BMPs are organized into the following categories by the International Stormwater BMP database (database): grass strip, bioretention, bioswale, composite, detention basin, green roof, manufactured device, media filter, porous pavement, retention pond, wetland basin and wetland channel (Leisenring et al. 2012a). These BMPs reduce runoff quantity, decrease runoff pollutants or do a combination of the two. Generally runoff quantity is reduced with a disconnected decentralized system of BMPs that mimicking the pre-development hydrology of an area. BMPs such as porous pavements and green roofs are prime examples of such BMPs and are considered low impact development (LID) BMPs. Low impact development BMPs can also reduce pollutant concentrations and restore groundwater levels. Other BMPs such as retention ponds, bioretention and media filter are primarily used to remove common stormwater pollutants. Figure 1

(Leisenring et al. 2012a) demonstrates influent and effluent concentrations of total suspended solids (TSS) for different BMP types. As seen effluent quality 
varies suggesting certain BMP types a will be better at removing TSS than others.

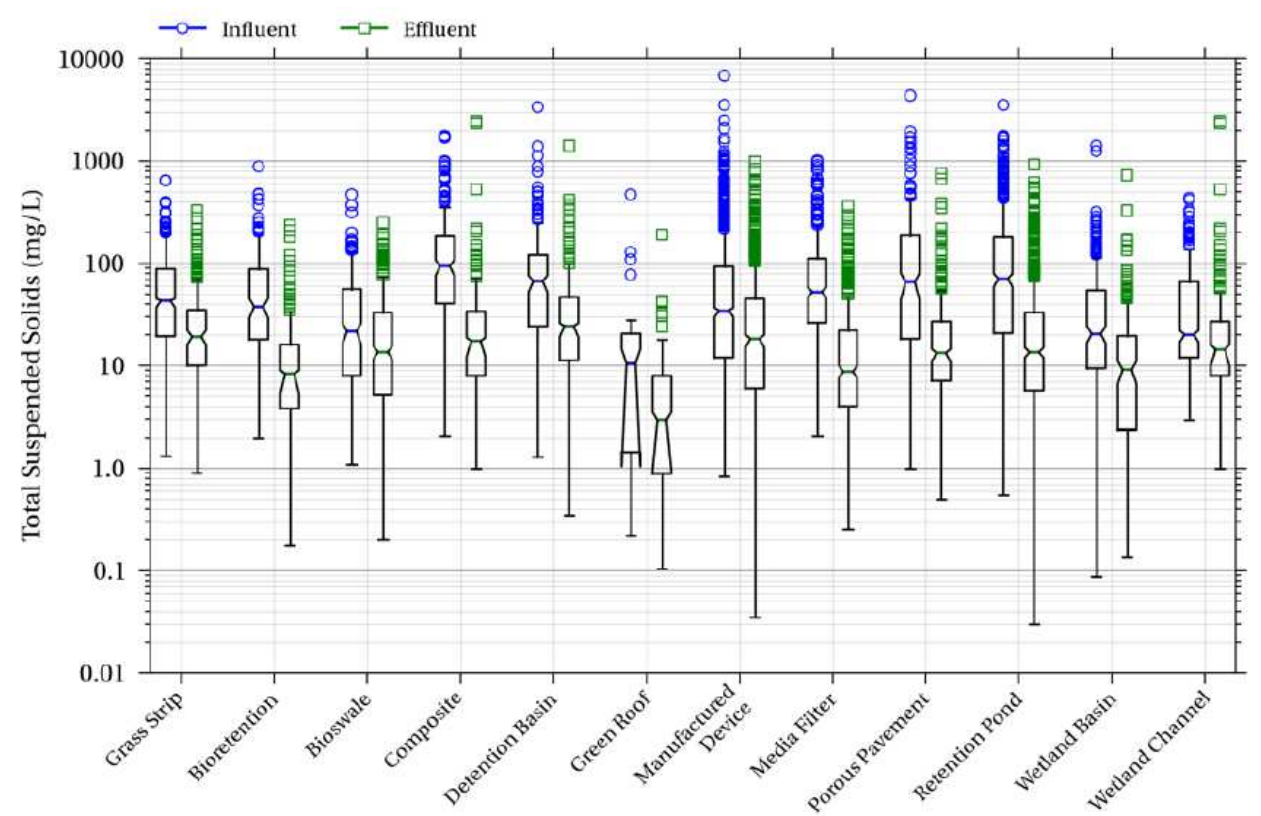

Figure 1: TSS influent and effluent concentrations for a variety of BMPs (Leisenring et al. 2012a)

\subsection{Manufactured BMPs}

The BMP tested in this paper is a manufactured device type BMP.

Manufactured device BMPs encompass a wide variety of design components which can accomplish various treatments processes. Manufactured BMP components are designed to provide treatment by filtration, sedimentation, skimming, sorption, straining and disinfection. The BMP database (Leisenring et al. 2012b) categorizes the performance of these devices by the process in which they treat stormwater. Treatment categories are filtration, inlet insert, multi process, physical manufactured device, oil/grit separators 
and baffle boxes, biological filtration and physical with volume control type. Physical manufactured devices use gravitational settling as the treatment process. Biological filtration uses a filtration device that supports plant, bacterial and or biofilms. The physical with volume control manufactured devices category uses detention vaults, other structures that allow infiltration, or pipes to reduce stormwater pollution. The filtration, inlet insert, baffle box and oil/grit separator subcategories are self-explanatory in respect to treatment mechanism.

\subsection{Effluent Quality of Manufactured Devices}

As expected each subcategory within manufactured devices performs differently depending on the pollutant considered. However, general removal trends for manufactured devices have been established using the database. All manufactured devices were shown to significantly reduce TSS, especially biological filtration, filtration, multi-process and physical with volume control subcategories. None of the manufactured devices were shown to significantly reduce dissolved copper, dissolved lead and dissolved zinc while total copper, lead and zinc were reduced best with the multi-process subcategory. All manufactured device BMPs reduced total phosphorous significantly, except oil/grit separators and baffle boxes. As with dissolved heavy metals, manufactured devices did not significantly reduce dissolved phosphorus. Certain subcategories were shown to significantly reduce TKN and NOx, 
however the majority of manufactured devices were ineffective at removing TKN and NOx (Leisenring et al. 2012b).

From performance data for manufactured devices the database shows that this BMP type is constrained in that no significant reduction in dissolved heavy metals or dissolved phosphorous is provided. Additionally the majority of manufactured devices are ineffective at removing TKN and NOx; if oxygen demanding substances or dissolved heavy metals in runoff requires treatment a manufactured device will likely be ineffective. Manufactured devices provide excellent treatment for certain pollutants and have a comparatively small footprint. Additionally conditions such as lack of space, high ground water level and poor soil infiltration can make a manufactured device the BMP of choice. Also certain industrial applications may require that a manufactured device like an oil/grit chamber be used.

A variety of protocols are referred to when assessing TSS concentrations and loads entering and exiting a BMP. Protocol selection depends on the regulatory agency overseeing environmental compliance, the type of device, if TSS concentrations will be measured during actual events, or if synthetic events will be created. The International Stormwater BMP Database previously mentioned has extensive information using storm events available. Information includes influent and effluent BMP pollutant data, 
watershed properties, hydrological data, BMP costs, BMP design parameters and more. Additionally, the database project publishes reports which summarize data and provide guidelines for statistical analysis. The Leisenring et al. (2011) report provides background information on causes of contaminated stormwater runoff, removal mechanisms, recommendations on BMP selection and design and regulatory context. Ongoing data collection and analysis from the database is expected to increase our understanding of BMP performance and stormwater pollution. As our understanding of stormwater pollution and BMP performance increases new methods and technologies are made available that need to be tested. Much analysis can be done using the database, for example figure 2 , which shows the pairing influent and effluent TSS event mean concentrations (EMC). 


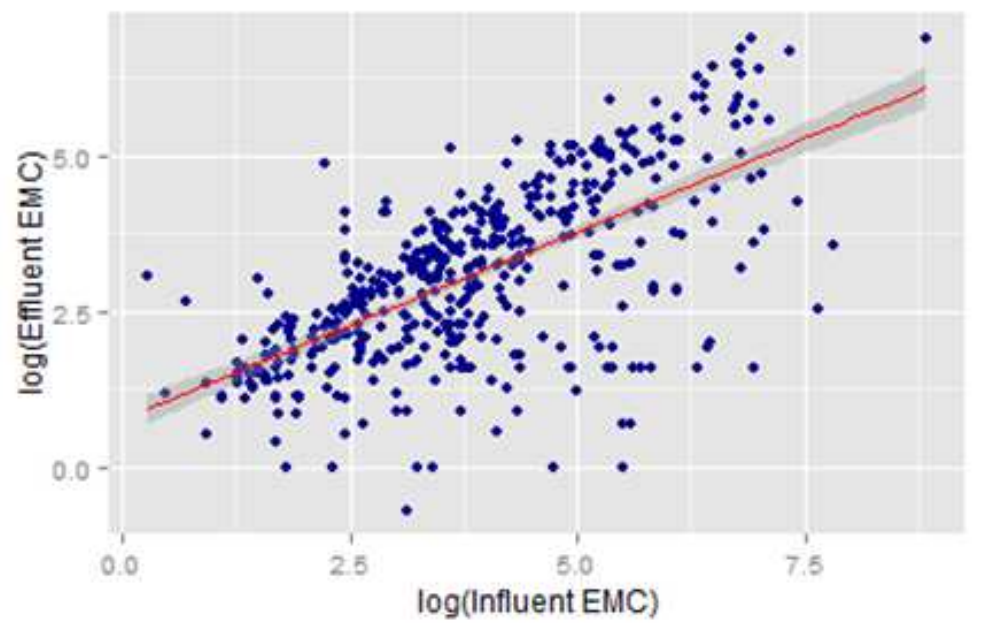

Figure 2: Paired influent/effluent event mean concentrations of TSS for manufactured devices with a primary treatment of processes of density/gravity/inertial separation and sedimentation

From the figure it is observed that a manufactured device will likely be effective at removing solids in the laboratory experiment and that effluent quality from BMPs using this treatment process is likely to depend on influent concentration. Further statistical analysis regarding influent effluent TSS relationship for this primary treatment process is necessary.

\subsection{Optimal Choice of a BMP or Manufactured Device}

Data for storm weighted performance of BMPs for solids, bacteria, metals and nutrients can be found by BMP category in the aforementioned database. Performance data can be used in a category level BMP analysis to determine if the BMP in question provides a statistically significant reduction of a given pollutant. However, since pollutant loading varies and runoff characteristics 
for a given set of conditions have not been established, engineers must rely on professional judgment when selecting a BMP for pollution reduction. To complicate the matter there are a large variety of BMP categories. Some BMP categories have subcategories and BMPs of the same types may be sized or designed differently; in other words, there are a large variety of BMPs to choose from, and as industrial NPDES stormwater permit managers know, BMPs selected by engineers do not always provide effluent quality that meets permit benchmarks. A more scientific approach considering influent characteristics for a given set of conditions would ensure the appropriate pollution reduction BMP is selected.

\subsection{Research Hypotheses}

It is hypothesized that a statistically significant correlation exists between the PSD of solids in stormwater and BMP removal efficiency for management practices using sedimentation as their primary treatment process. It is further hypothesized that literature data on solids-associated pollutant concentrations by size can be used to predict solid bound pollutant concentrations in effluent provided a correlation exists between PSD and removal. The hypotheses, if validated, can be used to show that as PSD or particle loading changes, due to any number of factors, the effluent quality from a BMP changes. 


\section{Chapter 3: Experimental Methods}

3.1Background on Experimental Testing of Manufactured BMPs

Regulatory agencies such as the State of Washington Department of Ecology

Howie et al. (2011) provide a protocol for full scale laboratory testing of manufactured BMPs. Additionally full scale manufactured BMPs have been tested at universities, (T. Schwarz and Wells 1999 ; Wilson et al. 2007) which provide guidance on conducing BMP experiments using simulated storm events. Depending on the agency, and the intended application of the BMP testing requirements vary. For assessing TSS, the protocol generally requires a steady introduction of solids with similar characteristics to those of stormwater at typical stormwater concentrations. The protocol requires tests be run at various flow rates relative to the devices treatment capacity at a number of influent concentrations representative of high, mean and low storm intensities and TSS loadings.

\subsection{Simulated Stormwater Experiment}

The first phase of the experiment involved testing a manufactured device under a synthetic storm event to assess the devices ability to remove TSS. A technical report was issued by Portland State University by Gorski and Fish (2012) for the Jensen Precast company, who funded the experiment. Mohr Separation Unit, Experimental Setup and Sample Collection sections herein are from that report. 


\subsubsection{The Mohr Separation Unit}

Mohr Separations Research (MSR), Lewisville, TX produces an enhanced gravity separator that utilizes a system of multiple angle plates to slow the flow of water, minimize turbulence, reduce rise/settling distance, provide solid/oil removal paths and enhance coalescing of oil droplets.

Influent to the MSR unit first enters a disengaging chamber where larger solids can settle and bulk oil rises to the surface. From the disengaging chamber water enters the inlet chamber where the flow is distributed by a baffle before entering the coalescing plate system where liquid solid separation is increased. Within the coalescing system light non aqueous phase liquids (LNAPL) merge and rise along paths through perforations in the plates. LNAPLs are subsequently collected in a chamber while solids are directed along paths to the bottom of the unit. After flowing through the coalescing plates water passes over an adjustable weir and exits the system.

\subsubsection{Experimental Setup}

An MSR-11P polypropylene separator, equipped with 30 coalescing plates having approximately 2 square feet of coalescing area each and plate spacing of approximately $8 \mathrm{~mm}$, was installed in the Hydraulics Laboratory in the Portland State University Engineering Building. The setup may be observed in figure 3. To supply required flow rates a water supply tank was connected to a centrifugal pump was used (Dayton model \#5k476C). The pump fed into 
the system via a gate valve and inline flow meter which allowed for variable flow rates. Solids were introduced at the crown of the influent pipe in the form of a well-mixed slurry using a peristaltic pump (Pulsafeeder model \# VSP-20) to provide a consistent delivery rate. The desired influent concentrations of solids were achieved by adjusting the solids/water ratio of the slurry. The slurry was mixed and maintained as a uniform suspension using a mounted electric drill with mixer attachment. Influent with a specified solids concentration was introduced to the MSR unit using a 1.5" PVC pipe and exited the unit under free fall conditions into a trough located below the unit. Preliminary tests were conducted to ensure accurate and consistent flow rates and solids influent rates.

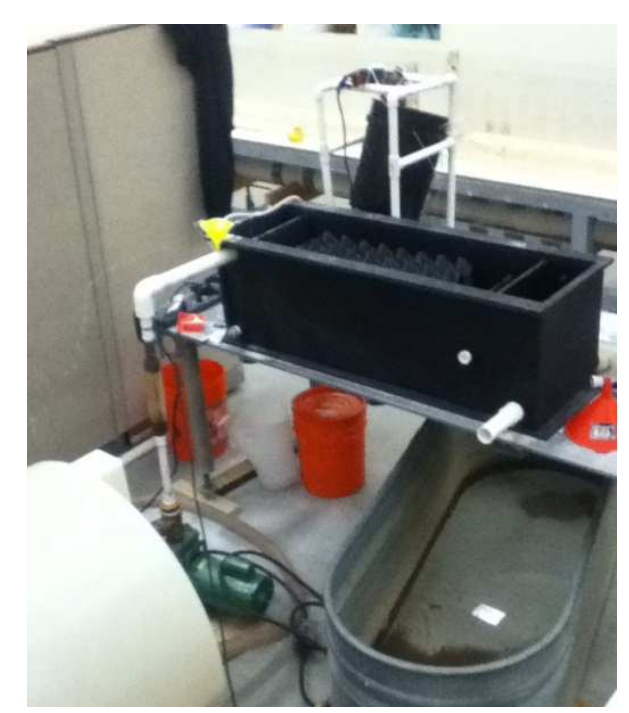

Figure 3: Photograph of simulated stormwater experiment 


\subsubsection{Simulating Stormwater TSS}

To achieve consistent and reproducible results we used Sil-Co-Sil 106 (SCS), a commercially available ground silica product as the source of influent solids. SCS is manufactured by U.S. Silica and has a median particle size of $19 \mu \mathrm{m}$, with a PSD shown in figure 4 , SCS is $99.8 \%$ pure silica and has a specific gravity of 2.65. Regulatory agencies such as the Washington State Dept. of Ecology require SCS to be used as the testing solids for assessing TSS removal of a stormwater treatment device in the laboratory(Howie et al. 2011). Use of this commercially available testing media facilitates performance comparisons of different technologies and ensures the experiment can be reproduced. It also has a consistent and known proportion of the very fine particles that are often of greatest concern in stormwater management. 


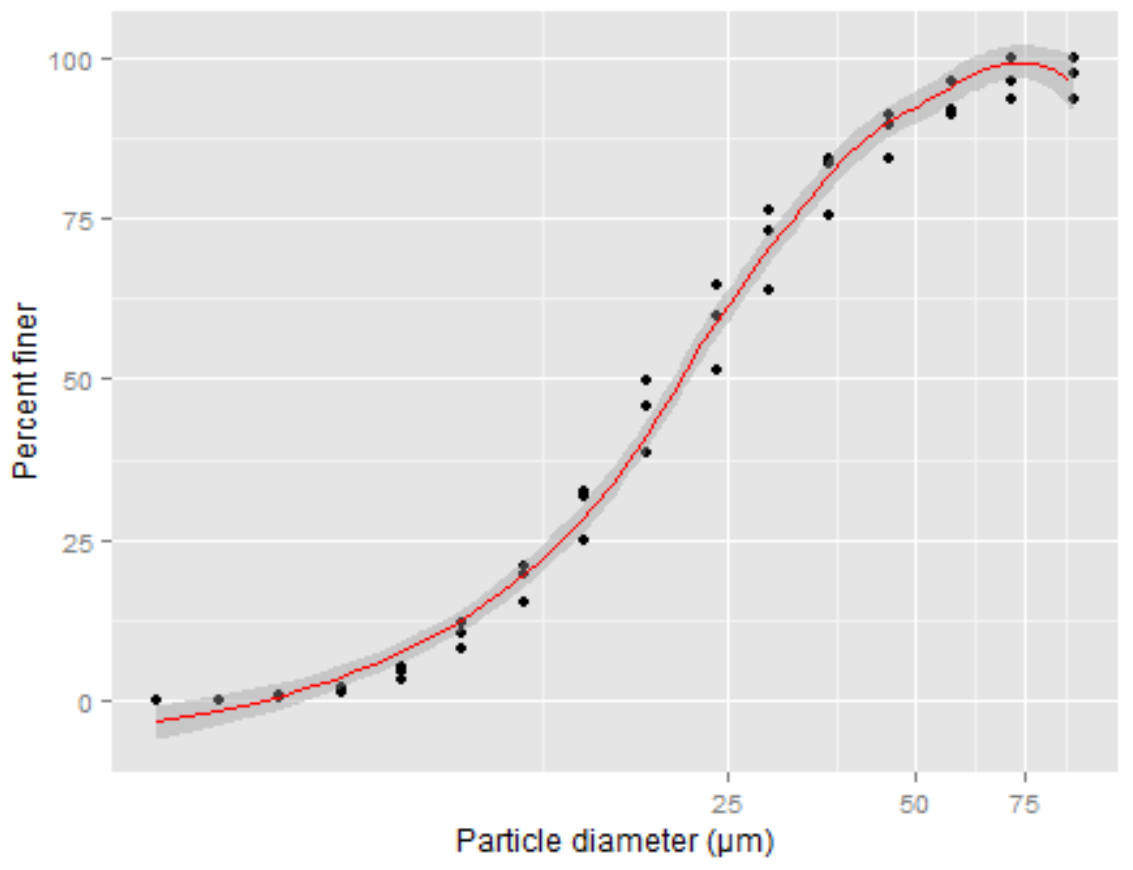

Figure 4: PSD of SCS as determined using the HIAC +9703 particle counter

\subsubsection{Sample Collection and TSS Analysis Method}

Samples were collected at three influent TSS concentrations (50, 100 and 200 $\mathrm{mg} / \mathrm{L})$ and three different flow rates (5, 10 and 15 GPM) for a total of nine operational conditions. Flow rates were specified by the product manufacturer and TSS concentrations represent typical influent concentrations required by regulatory agencies for assessing removal. Washington State Dept. of Ecology states that tests be run at influent TSS concentrations of 100 and $200 \mathrm{mg} / \mathrm{L}$, but strongly encourages tests be run at lower influent concentrations as well (Howie et al. 2011). 
Four effluent grab samples were taken at different times for each one of the specified influent and flow rate conditions, a total of 36 grab samples were analyzed. The unit was allowed to cycle a minimum of three volumes (100 gallons) before samples were collected. On average samples were collected every 25 gallons for the $50 \mathrm{mg} / \mathrm{L}$ run, every 31 gallons for the $100 \mathrm{mg} / \mathrm{L}$ run, and every 32 gallons for the $200 \mathrm{mg} / \mathrm{L}$ run . Samples were analyzed according to EPA method 106.2 (E. The United States Environmental Protection Agency 1971). Each Whatman Glass Microfiber Grade GF/C Filter was placed in a $47 \mathrm{~mm}$ Pall Magnetic Filter Funnel and suction flask with vacuum attachment, then washed with three successive $20 \mathrm{~mL}$ aliquots of distilled water while vacuum was applied. After washing, filters were placed in a drying oven at $105^{\circ} \mathrm{C}$ for one hour. After drying, filters were placed in a desiccator. After cooling, the weight of each filter was taken to ensure a constant mass was obtained. Filters were stored in a desiccator at room temperature until immediately before use. Immediately before being placed in the suction apparatus for analysis masses were taken of each filter. Each filter was then placed in the $47 \mathrm{~mm}$ Pall Magnetic Filter Funnel with suction flask and vacuum attachment. An aliquot of $200 \mathrm{ml}$ for each well mixed effluent sample was measured using a graduated cylinder and run through the filter while vacuum was applied. The filter funnel and graduated cylinder were then rinsed with a small amount of distilled water to ensure all effluent 
solids had been captured by the filter. The vacuum was then turned off and the filter was removed and placed into a drying oven for one hour at $105^{\circ} \mathrm{C}$, after drying filters were cooled in a desiccator and weighed. Effluent concentrations were calculated as follows:

$$
\text { Effluent Concentration } \left.\left(\frac{m g}{L}\right)=\frac{A-B}{D}(1000) \text { (Equation } 1\right)
$$

Where A is the weight of filter and captured solids (mg), B is the weight of the filter $(\mathrm{mg})$ and $\mathrm{D}$ is the sample volume $(\mathrm{ml})$.

\subsection{Particle Size Distribution Testing}

\subsubsection{Background}

As seen in table 1, adapted from Li et al. (2005), a number of particle sizing techniques can be used to determine stormwater runoff quality. Techniques measure particle properties such as sedimentation, light obstruction, light diffraction and differential resistance. Different methods have different advantages, and current techniques that measure PSDs fine particles all have limitations. It is noted by Hargesheimer and Lewis (n.d.), that different techniques can produce slightly different results. 
Table 1: Methods used, and details on methods for sizing particles in stormwater adapted from Grant et al. (2003)

\begin{tabular}{c|ccc}
$\begin{array}{c}\text { Property of particle } \\
\text { measured }\end{array}$ & Aspects Measured & Advantages & Limitations \\
Sedimentation & Gravity & $\begin{array}{c}\text { Results apply directly to } \\
\text { BMP design }\end{array}$ & Slow \\
Differential resistance & $\begin{array}{c}\text { Voltage proportional to } \\
\text { particle volume }\end{array}$ & $\begin{array}{c}\text { Results not affected by } \\
\text { particle shape }\end{array}$ & $\begin{array}{c}\text { May disrupt } \\
\text { fragile flocks }\end{array}$ \\
Light obscuration & $\begin{array}{c}\text { Voltage proportional to } \\
\text { particle area }\end{array}$ & $\begin{array}{c}\text { Results not affected by } \\
\text { particle nature }\end{array}$ & $\begin{array}{c}\text { May disrupt } \\
\text { fragile flocks } \\
\text { Light diffraction }\end{array}$ \\
Light intensity & $\begin{array}{c}\text { No calibration step } \\
\text { required }\end{array}$ & $\begin{array}{c}\text { Concentration } \\
\text { has great }\end{array}$ \\
Dynamic light scattering & Hydrodynamic effect & $\begin{array}{c}\text { Good for particle till } \\
1 \text { gm }\end{array}$ & $\begin{array}{c}\text { Long wait } \\
\text { time }\end{array}$
\end{tabular}

\subsubsection{The HIAC +9703 Particle Counter}

The particle counter used in this research is a HIAC +9703 which operates on the principle of light obscuration. The light obscuration sensor consists of a laser diode that provides light and a photodiode that detects obstructions in light. When particles pass through the sensor light is obstructed. The amount of light obstructed correlates to the size of the particle. Light obstruction is registered by the photodiode which sends an electric potential difference corresponding to the amount of light obstructed. Light obscuration sensors are well suited for fluids with high levels of particle contaminates. Light obscuration particle counters can be used to accurately size particle from $1.3 \mu \mathrm{m}$ to $600 \mu \mathrm{m}$, and this particular model sizes particles from $2.5 \mu \mathrm{m}$ to $300 \mu \mathrm{m}$. 
The sensor is connected to a counter device which converts electric potentials from light obstructions to particle counts. Liquid is drawn through the sensor at a constant rate by a syringe system connected to the counting device that draws between 1 and $10 \mathrm{ml}$ of fluid containing particles. 16 particle size bins may be measured using this HIAC and intervals may be specified. The counting device is equipped with a magnetic stirrer of variable speed to ensure the distribution of particle sizes is even throughout the sampling liquid.

\subsubsection{Experimental Methods}

The HIAC +9703 was calibrated to draw samples at .06liters per minute and drew $6 \mathrm{ml}$ aliquots per sample. The counter allows the user to specify 16 bins that the sensor registers counts at. A table of the bins used may be seen in table 8 , which is in the modeling chapter. Bins were spaced at a log interval as the transformation resulted in a more evenly distributed number of occurrences at bins than linear spacing.

Prior to particle sizing of effluent from the MSR unit, labeled and sealed HDPE bottles containing effluent from the simulated stormwater experiment were stored away from direct sunlight at room temperature. Immediately before particle sizing, HDPE bottles were placed in an ultrasonic bath for 5 minutes to break up particles clumps and to remove possible air bubbles. 
During particle sizing samples were gently mixed using a magnetic stirrer set to stir at $70 \%$ of maximum velocity. To ensure particles within the sample were evenly distributed. Occasionally an air bubble could be seen flowing out of the sensor which could have corresponded to false particle counts at larger sizes. To minimize false particle counts due to air bubbles each test was run twice, consecutively to ensure that data was roughly equivalent.

\subsection{Storm Solids Collection}

\subsubsection{Background}

On a large scale, correlation between land use type and EMCs of stormwater pollutants has not been shown to be statistically significant (Leisenring et al. 2012a). Likewise a more localized study by Isfahani (2013), in Portland also found no statistically significant correlation between land use and stormwater runoff quality. However, data reported from sites to regulatory agencies to comply with industrial stormwater permits show that on a site to site basis pollutant type and loading do vary. It is expected that as more data become available on both drainage basin characteristics and stormwater runoff pollutants, that statistically significant correlations can be established. A correlation between land use type, or some other drainage basin characteristic or combination thereof, and stormwater pollution would provide guidance in selecting the most appropriate BMP for specified drainage basin characteristics. 


\subsubsection{Collection Method}

Five sediment sample locations were selected based on human activity.

Selected sample locations are shown in table 2. Core samples of stormwater solids were collected, from the top of all facilities through manhole openings or an access hatch, in the case of sample 2 . The collection pipe consisted of a series of interlocking segments and was made air-tight so that once in the sediment, or in slurry, a seal could be made on the opposite end of the pipe using a hand and a core of sample could be extracted.

Not all samples were extracted in this manner. In the case of samples 4 and 5 sediment was too wet and the pipe collection system was ineffective. In these cases samples were collected using an extendable scoop. Best efforts were made to collect samples in a manner consistent at all sites, however sediment collection in high traffic areas was more rushed. Samples were collected in HDPE sealable containers and analyzed in a similar manner as described in the Particle Size Distribution section. 


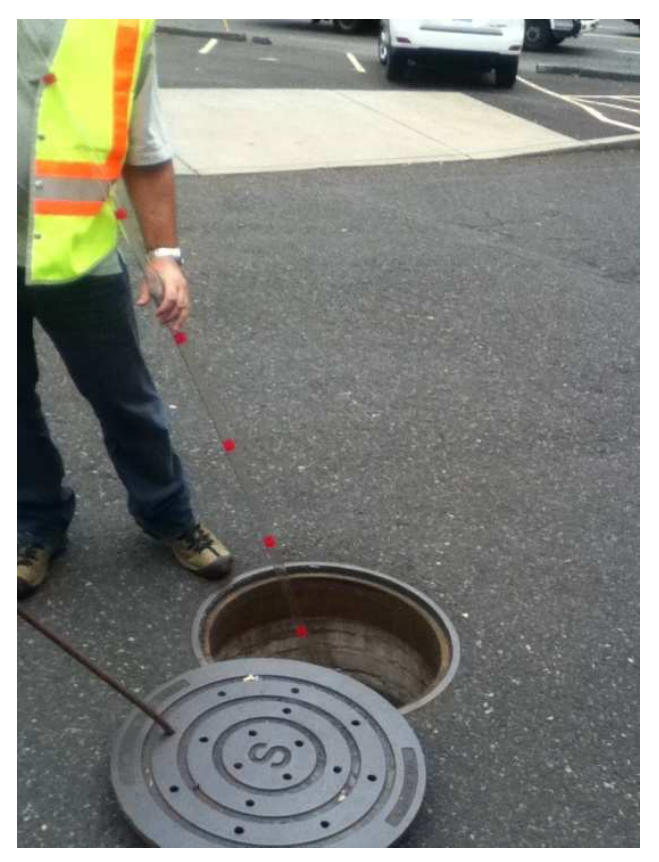

Figure 5: Todd Gunter, of the BES, collecting stormwater solids from sedimentation manhole using the described piping system

Table 2: Sample sediment deposition locations, land use type and traffic intensity

$\begin{array}{cccc}\text { Sample site } & \text { Sediment deposition location } & \text { Land use } & \text { Traffic } \\ 1 & \text { SED MH } & \text { Residential } & \text { Low } \\ 2 & \text { Manufactured BMP } & \text { Commercial } & \text { High } \\ 3 & \text { SED MH } & \text { Commercial } & \text { High } \\ 4 & \text { SED MH } & \text { Residential } & \text { Light } \\ 5 & \text { SED MH } & \text { Industrial } & \text { Medium }\end{array}$




\section{Chapter 4: Results}

\subsection{Gravimetric Results for TSS}

Gravimetric analysis results reported from the Gorski and Fish (2012) technical report discussed in the Simulated Stormwater section are as follows:

The TSS percent removal efficiency was calculated for each test condition as the difference of effluent and influent solids concentrations times 100. Box plots are used to represent variability in observations as four grab samples were taken for each of the influent conditions.

\subsubsection{TSS Concentration in $=50 \mathrm{mg} / \mathrm{L}$}

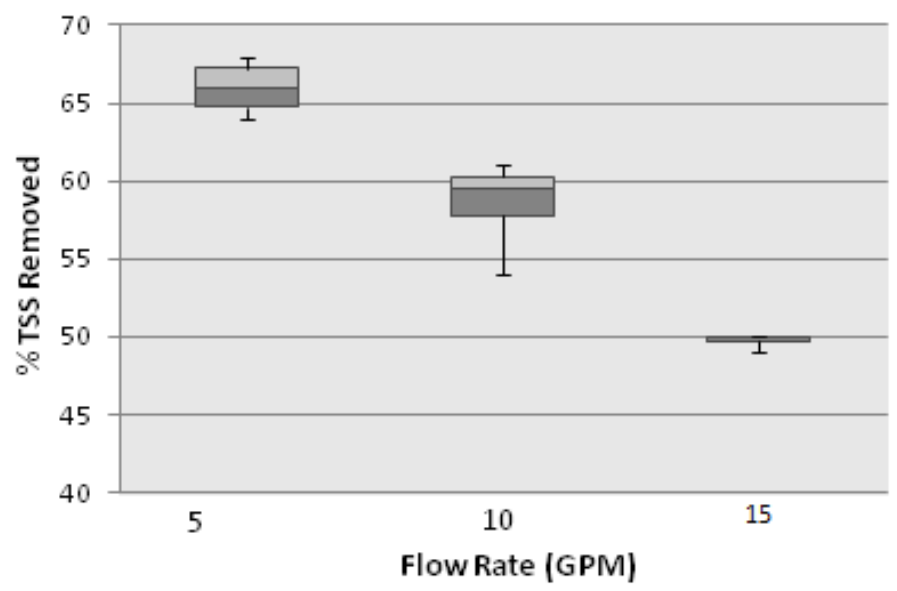

Figure 6: Box plots for \%TSS removal. Influent TSS=50 mg/L

Figure 6 shows that TSS removal by the MSR unit, with an influent concentration of $50 \mathrm{mg} / \mathrm{L}$, was generally between $50 \%$ and $66 \%$ and declined with increasing flow. Influent temperatures during sample collection ranged 
between 12.1 and $11.4^{\circ} \mathrm{C}$. Variability of measured effluent concentrations for this run do not correlate with volume cycled at the time of collection or flow rate.

\subsubsection{TSS Concentration in $=100 \mathrm{mg} / \mathrm{L}$}

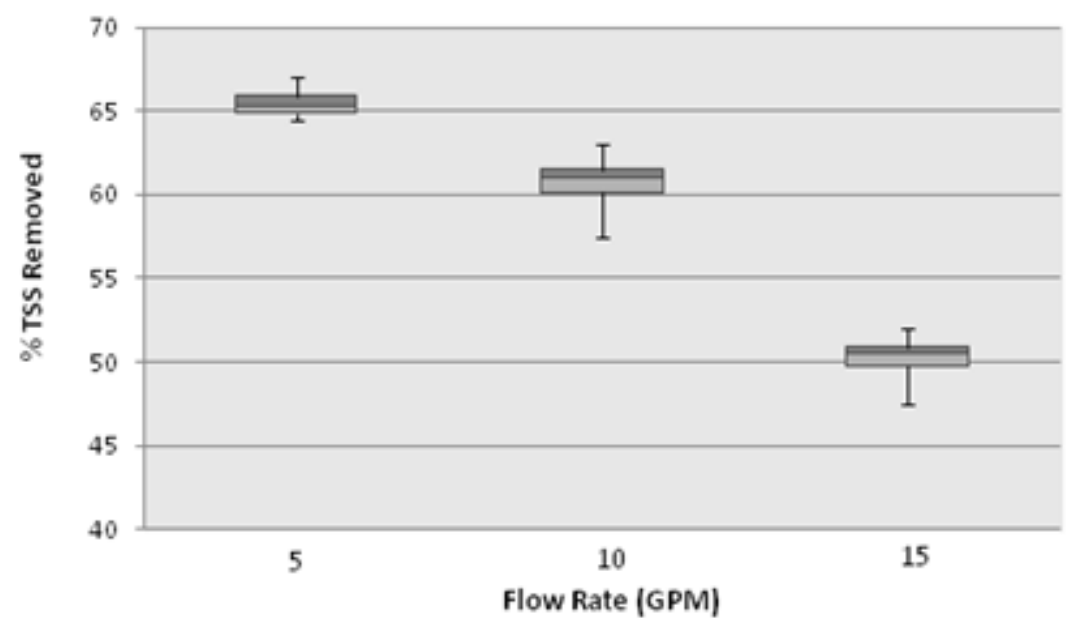

Figure 7: Box plots for \% TSS removal. Influent TSS=100 mg/L

Figure 7 shows a very similar pattern of TSS removal by the MSR unit with an influent concentration of $100 \mathrm{mg} / \mathrm{L}$. Once again removals ranged from about $66 \%$ at $5 \mathrm{GPM}$ to about $50 \%$ at 15 GPM. Influent temperatures during sample collection ranged between 11.7 and $15.0^{\circ} \mathrm{C}$. Two-tailed, paired T-tests were performed to compare influent concentrations of $50 \mathrm{mg} / \mathrm{L}$ and $100 \mathrm{mg} / \mathrm{L}$ at each flow rate. A Paired T-test was conducted at each flow rate to compare differences between the $50 \mathrm{mg} / \mathrm{L}$ influent concentration and the $100 \mathrm{mg} / \mathrm{L}$ influent concentration. Results from the T-test show the difference in 
removals observed at the two different influent concentrations as not statistically significant.

\subsubsection{TSS in $=200 \mathrm{mg} / \mathrm{L}$}

Figure 8 shows TSS removal of the MSR unit with an influent concentration of $200 \mathrm{mg} / \mathrm{L}$. Influent temperatures during sample collection ranged between 18.3 and $10.8^{\circ} \mathrm{C}$.

T-tests were performed at each flow rate to compare removal efficiencies observed at previous influent concentrations to removal observed at the $200 \mathrm{mg} / \mathrm{L}$ influent concentration. Results from the T-test show a statistically significant difference between the $200 \mathrm{mg} / \mathrm{L}$ influent concentration and subsequent influent concentrations at the 10 GPM flow rate but not at the 5 or 15 GPM flow rates. It is thought that difference would be statistically significant at all flow rates if more samples were analyzed.

As mentioned samples were collected on average every 32 gallons at this influent concentration; effluent solids concentration tended to increase at each successive grab for both the 10GPM and 15GPM flow rates. Variability in removal efficiency was not observed to correlate with volume cycled for other influent concentrations suggesting that some degree of re-suspension or scouring occurs in coalescing plate separators at higher flow rates and influent solids concentrations. It is also possible that the slurry with higher 
solids content behaved differently and short circuiting of the flow path occurred. To confirm observations the $200 \mathrm{mg} / \mathrm{L}$ test was rerun at 15GPM, results were the same.

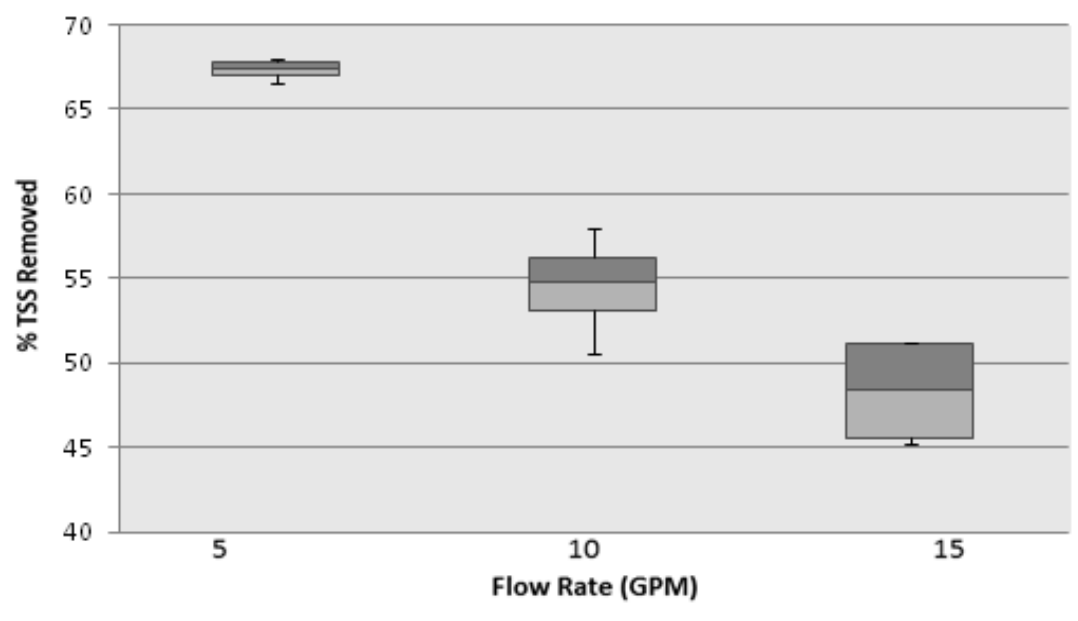

Figure 8: Box plots for \% TSS removal. Influent TSS=200 mg/L

\subsubsection{Summary}

Five number summaries and mean values for removal efficiencies at all influent concentrations and flow rates can be seen in Table 3. Variance in removal efficiencies is relatively small at all flow rates and influent concentrations. 
Table 3: Statistical summary of gravimetric testing at all operational conditions

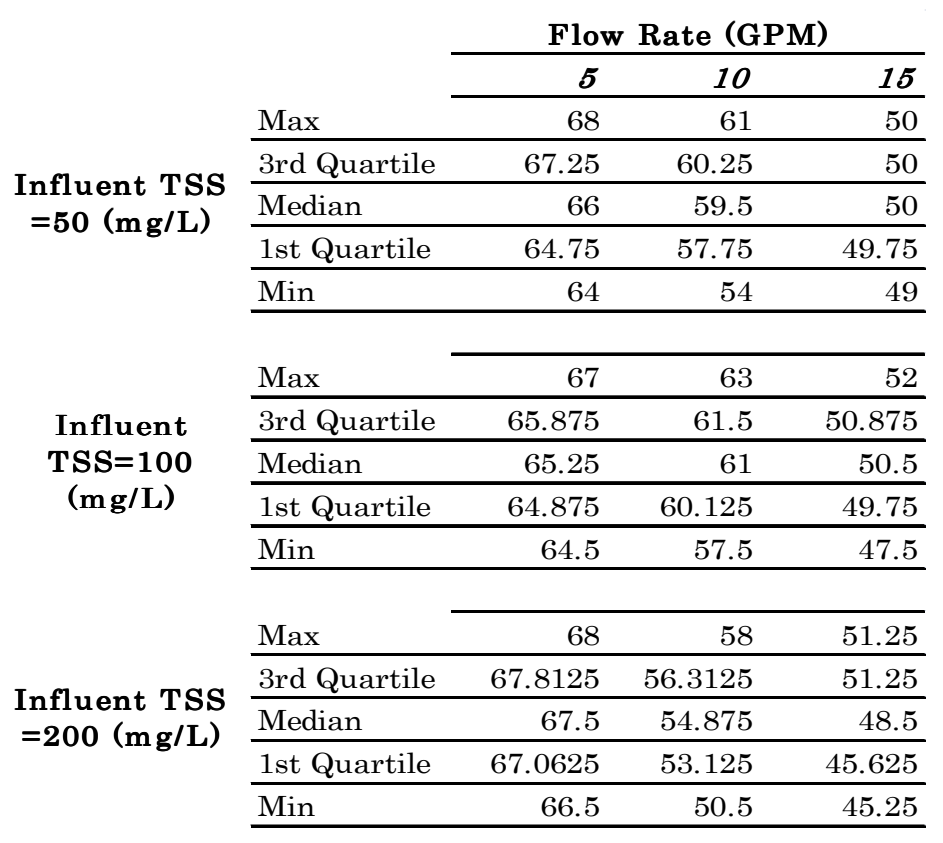

Table 4 shows $\mathrm{P}$ values from two tailed T-tests comparing removal efficiencies observed at previous influent concentrations to removal efficiencies observed at the $200 \mathrm{mg} / \mathrm{L}$ influent concentration. F-tests were performed on each data set to determine if equal variance or unequal variance T-tests would be used. As seen in table 3, the $200 \mathrm{mg} / \mathrm{L}$ influent concentration at 10 GPM displays a statistically significant difference. There is unanimous consensus among the research and regulatory community that TSS concentration in will affect removal, so while other flow rates at the 200mg/L influent concentration do not display a statistically significant difference it is likely due to the small number of samples taken. 
Table 4: $\mathrm{P}$ values for two-tailed T tests comparing 50 and $100 \mathrm{mg} / \mathrm{L}$ influent concentrations to the $200 \mathrm{mg} / \mathrm{L}$ influent concentration

$\begin{array}{ccc}\text { Flow Rate (GPM) } & \text { T-test type } & \text { P value } \\ 5 & \text { Equal Variance } & 0.058 \\ 10 & \text { Equal Variance } & 0.018 \\ 15 & \text { Unequal variance } & 0.424\end{array}$

\subsection{Particle Size Distribution}

\subsubsection{Reproducibility of Particle Sizing}

To demonstrate PSD reproducibility results the difference proportion (DP), which represents the difference between a duplicate pair can be used.

$$
\left.D P=\frac{100\left(2\left|N_{1}-N_{2}\right|\right)}{\left(N_{1}+N_{2}\right)} \quad \text { Equation } 3\right)
$$

In this case, $N_{1}$ and $N_{2}$ are the counts registered at a particular size range of particles for two consecutive tests.

Table 5: Difference proportion mean and variance for 10 duplicate samples and mean count numbers

\begin{tabular}{lcccccccc} 
Statistical & \multicolumn{9}{c}{ Particle diameter range $(\mu \mathrm{m})$} & & Total \\
\cline { 2 - 6 } \cline { 3 - 6 } Parameter & $3-5$ & $5-9$ & $9-15$ & $15-24$ & $24-36$ & $36-90$ & & 30 \\
\hline DP mean & 0.8 & 0.5 & 0.8 & 1.7 & 4.6 & 12.7 & 0.12 \\
DP variance & 0.2 & 0.1 & 1.0 & 1.7 & 12.5 & 36.5 & 0.005 \\
N mean (count/mL) & 5069 & 10860 & 7710 & 2997 & 528 & 69 & 21568
\end{tabular}

DP mean and DP variance across different size ranges are similar to DP mean and variance values for 11 duplicate samples of stormwater analyzed using a Nicomp AccuSizer 780 optical particle sizer module, equipped with auto dilution system and a light scattering/extinction sensor, at UCLA (Li et 
al. 2005). The UCLA study revealed a similar trend of increasing DP mean and variances with increasing particle size. The study reported low mean, and low variance values of 9.5 and .1, respectively. A high mean DP of 75.6 and variance values of 64.2 was reported at particle diameter ranges of 200$1000 \mu \mathrm{m}$. While diameter range was different in the UCLA study we see that a degree of difference between identical samples is acceptable due to particle measuring techniques. Mean counts per ml measured for particles smaller than $10 \mu \mathrm{m}$ were however lower than mean counts measured in the UCLA study. In part count difference is due to different solid types, however sampling equipment used in the UCLA study is more sophisticated. Regardless, particle sizing techniques used in this experiment are accurate as seen in observing the d50 value for SCS determined, seen in figure 9, which is approximately $19 \mu \mathrm{m}$, the same value for SCS reported by Ecology (Washington Department of Ecology 2004).

\subsubsection{PSD of Simulated Storm}

As previously covered in the Simulating Stormwater TSS section, SCS is an accepted stormwater suspended solids substitute; SCS has a PSD that tends toward fine particles that are of the greatest concern in stormwater management. The simulated PSD of TSS in stormwater runoff has implications outside of BMP effluent quality. The simulated PSD of TSS in stormwater runoff, combined with a additive non-parametric model based 
correlating PSD and sorbed metal concentrations can be used to identify which size particles in stormwater runoff contribute the most of a particular pollutant load.

Figure 9 shows the PSD of SCS, what is assumed for purposes of the model to represent a PSD of suspended solids in a storm event. Three separate samples were run at a solids concentration of $50 \mathrm{mg} / \mathrm{L}$.

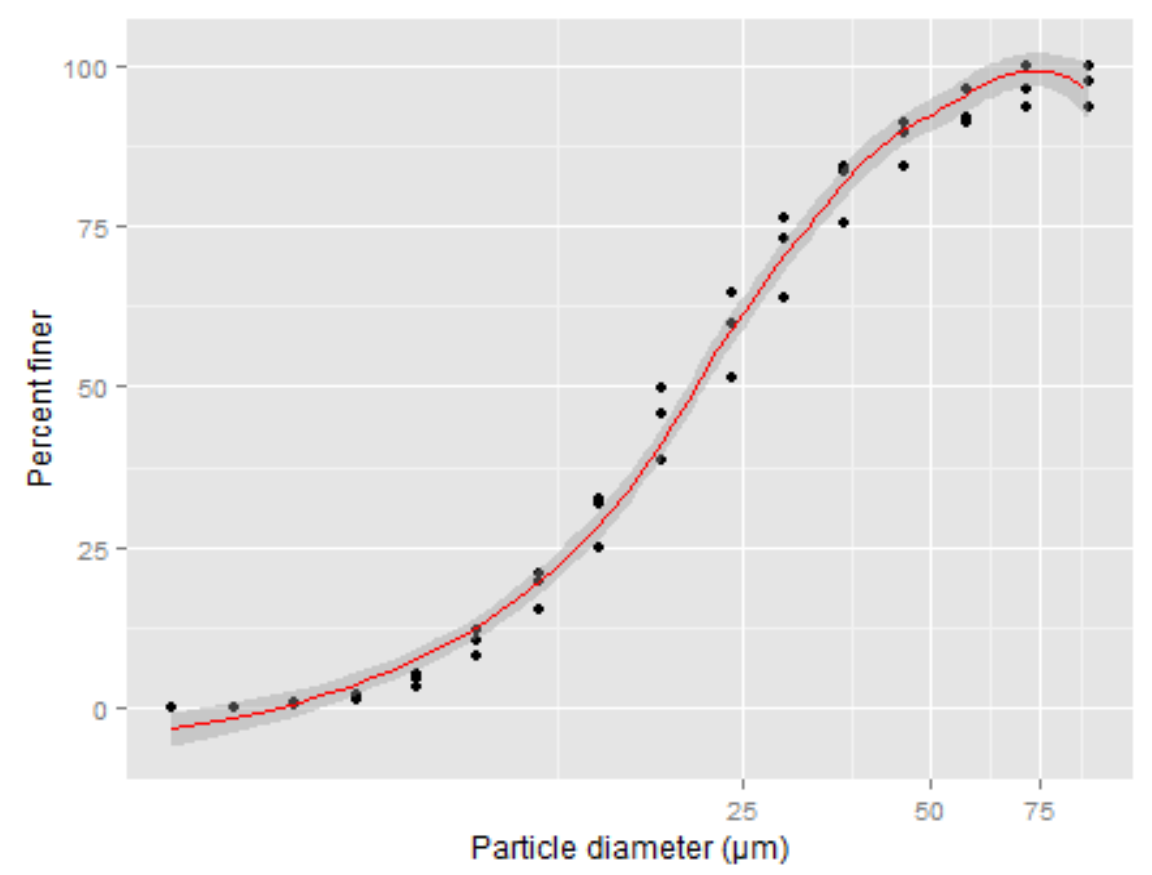

Figure 9: PSD of SCS as determined using the HIAC +9750 The HIAC +9750 particle counter reports count increments assuming particles are spherical, therefore masses of particles may be estimated assuming a constant density. Figure 10 the shows mass per particle size 
range removed by the MSR unit under simulated stormwater conditions and removal by size. By mass it is seen that particles between the ranges of approximately 15 to 25 microns account for the majority of mass removed. 

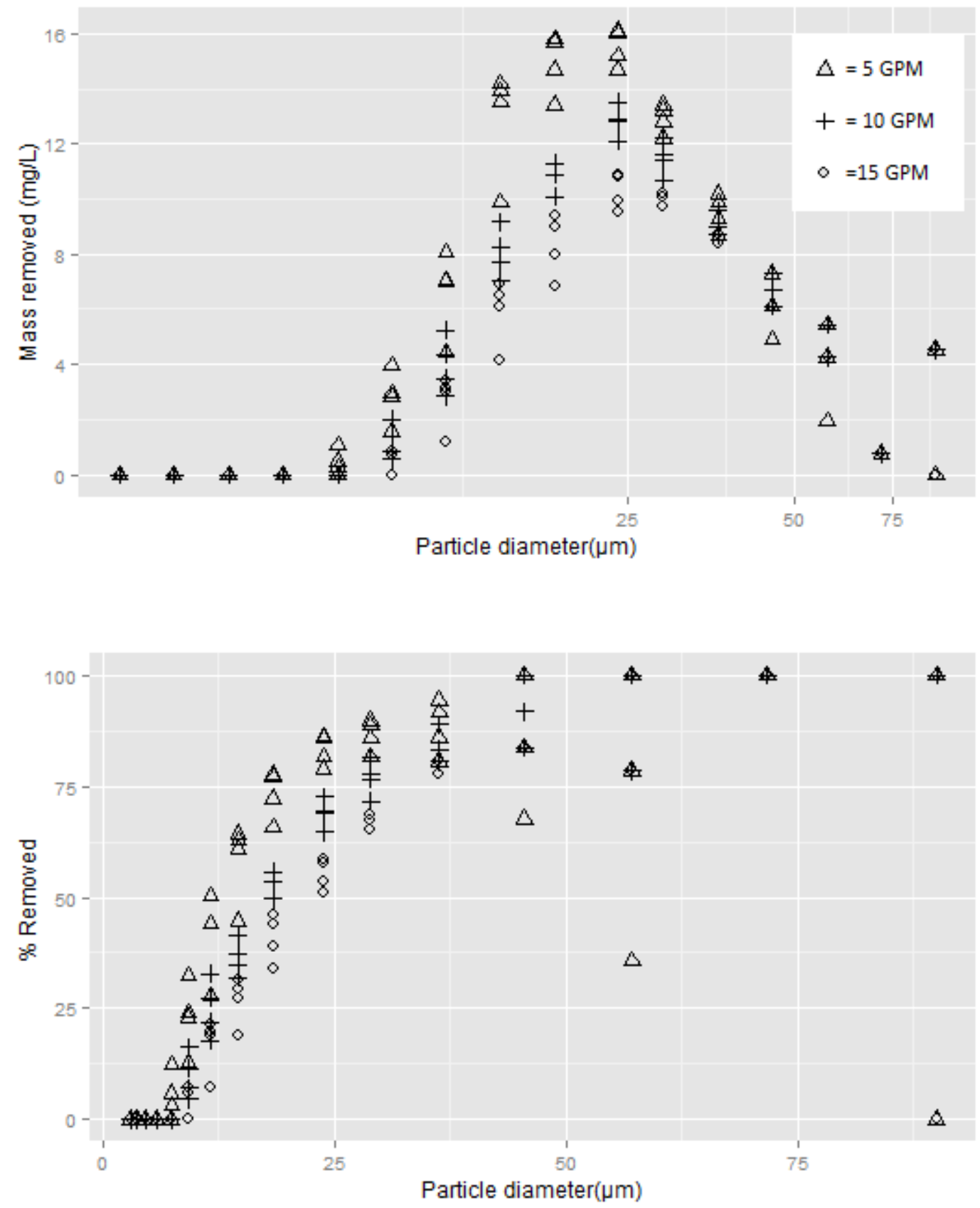

Figure 10: Removal of particle size by mass and percent for simulated storm solids 
To compare total mass reduction of solids using the two methods equation 4 was used on particle size data. As seen the total reduction by incremental particle size method is consistently lower than gravimetric TSS reduction.

$\frac{\sum \text { mass in at specified size }-\sum \text { mass out at specified size }}{\sum \text { mass inat specified size }}$ $\sum$ Mass in at specified size

(Equation 4)

Table 6: Particle mass reduction from summation of assumed spherical particles counts into and out of unit and mass reduction of particles determined using gravimetric method

\begin{tabular}{ccc} 
& Total Reduction by incremental Partice size & Gravametric TSS reduction \\
\cline { 2 - 3 } 5 GPM & 0.62 & 0.65 \\
& 0.58 & 0.67 \\
& 0.62 & 0.68 \\
& 0.58 & 0.64 \\
\hline \multirow{3}{*}{$10 \mathrm{GPM}$} & 0.46 & 0.6 \\
& 0.49 & 0.54 \\
& 0.51 & 0.59 \\
\multirow{3}{*}{$15 \mathrm{GPM}$} & 0.52 & 0.61 \\
& 0.42 & 0.5 \\
& 0.42 & 0.5 \\
& 0.44 & 0.49 \\
\hline
\end{tabular}

\subsubsection{PSD of Collected Stormwater Particulates}

The largest mean particle size was observed at sample location 1 , a residential low traffic area. Solids from this location appeared earthy and were heavy with decaying plant matter. Sample 2, taken from commercial high traffic area had a mean particle diameter about half that; slurry taken at location 2 was in the form of a semi viscous black sludge. Sample 2, which visually appeared most contaminated contained sludge worm (Tubifex 
tubifex). While samples 2 and 3 were taken from different facility types, their median particle sizes are similar. Interestingly both samples 2 and 3 were collected at commercial locations with high traffic. Like sample 2, sample 3 was a sludge-like consistency that appeared heavily polluted. Samples 4 and 5 , taken in different land use and traffic pattern areas were found to have similar mean particles sizes. While land use and traffic patterns varied between samples 4 and 5 the geographic location was close. Both samples 4 and 5 appeared to have degree of plant matter. 

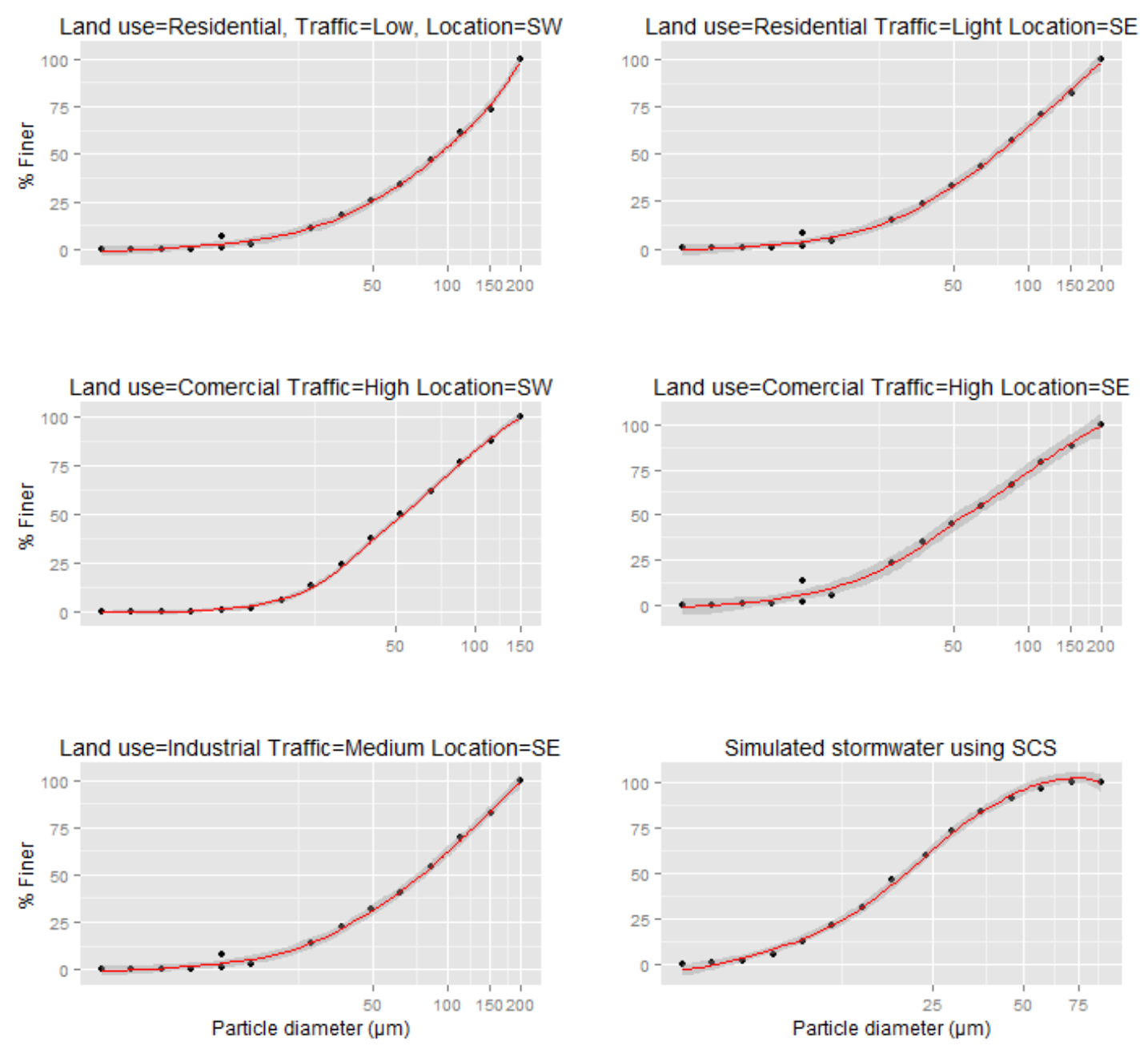

Figure 11: Particle size distributions of collected storm solids

\subsubsection{Previous Particle Sizing Studies in Portland, Oregon}

Tracy S. Schwarz (1999) collected and analyzed stormwater runoff in

downtown Portland and in a parking lot in East Portland by manually collecting one liter samples at two minute intervals for the first hour of a storm event, and collecting samples at 30 minute intervals for the rest of the storm. Collecting runoff in this manner provides data that is more 
representative of solids entering a device over time and accounts flushing of deposited particles.

Samples collected in downtown Portland were shown to have a mean diameter that ranged between $28 \mu \mathrm{m}$ and $95 \mu \mathrm{m}$ depending on when the sample was collected. Samples collected from the lot were shown to have a median particle size between $34 \mu \mathrm{m}$ and $80 \mu \mathrm{m}$ at differing points during the storm. Additionally, Schwarz provides extensive information on previous studies measuring solids concentrations in stormwater runoff in different areas of Portland, such as work by Strecker et al. (1997) who used monitoring stations to measure suspended solids concentrations at different locations and land uses. The study by Strecker shows area of low anthropogenic impact tending to have lower mean TSS concentrations, however outliers are present. 
Chapter 5: Modeling of Experimental Data, Observations and Implications

\subsection{Conceptual Model}

The following conceptual model is based on a hydraulic model for sedimentation in stormwater detention basins from Takamatsu et al. (2010). Equations 5-7 are presented as published in their work.

Under plug flow conditions flow velocity in $\mathrm{x}$ is uniform through the vertical cross sectional area and flow velocity is in $\mathrm{z}$ is uniform through the horizontal cross section. The longitudinal component of flow velocity at a local point $\mathrm{x}$, may be expressed using equation 5 .

$$
\left.u(x, t)=\frac{Q(x, t)}{B \times h(t)} \quad \text { (Equation } 5\right)
$$

Where $\mathrm{h}(\mathrm{t})$ is equal to water height at time t. The local vertical velocity is given by equation 6 .

$$
w(z, t)=\frac{d h(t)}{d t} \times \frac{z}{h(t)} \quad \text { (Equation 6) }
$$

It is assumed a particle at points $(\mathrm{x}, \mathrm{z})$ follows the horizontal velocity component of flow, and will be subject to vertical settling. Accordingly, vertical motion of the particle can be expressed as follows:

$$
\frac{d z}{d t}=w(z, t)-v_{s} \quad \text { (Equation 7) }
$$


Since data collection began under equilibrium conditions mass conservation applies according to equation 8 .

$$
\frac{d V}{d t}=Q_{\text {in }}-Q_{\text {out }}=0 \quad \text { (Equation 8) }
$$

The volume of the flow does not change, and the bed of the MSR unit is flat so the vertical velocity component of flow is assumed to be negligible. It is assumed particles follow an ideal horizontal flow reactor trajectory and that particles were introduced at the surface of the unit. With these assumptions the velocity of a particle in the unity can be expressed using equation 9 .

$$
\vec{A}=u \hat{\imath}-v_{s} \hat{k} \quad \text { (Equation 9) }
$$

Experimental conditions were such that all particles were smaller than $100 \mu \mathrm{m}$, as such Reynolds particle numbers are less than 1. At Reynolds particle numbers of less than and approximately equal to 1.0 Stokes Law can be used to make an accurate estimate of the particles velocity. For each particle size and flow condition a trajectory can be determined. The particle path's endpoint, which will depend on the depth and length of the unit is then used to determine the critical settling velocity under a flow condition. With a critical settling velocity removal percentage of particle size $\mathrm{x}$ is determined by equation 10, as reported in Takamatsu et al. (2010). 


$$
F(x)=\left\{\begin{array}{c}
\frac{v_{s}(x)}{v_{s c r i t}}, v_{s}(x) \leq v_{\text {scrit }} \\
1, v_{s}(x)>v_{\text {scrit }}
\end{array} \quad \text { (Equation } 10\right)
$$

The conceptual model assumes that in order to be removed, the particle must reach the bottom of the water column before traveling the length of the unit; the particle size with a trajectory to the bottom of unit having traveled the complete length of the unit corresponds to the critical velocity. One function of the coalescing plate system designed by MSR is that it reduces the distance that a particle must travel in order to settle. For this model the 2 foot long coalescing plate portion of the unit was assumed to be the settling zone, it was further assumed that particles began at the top of the plate system. Based on initial gravimetric testing is was estimated that the coalescing plate system reduced settling distance by one half.

As shown in figure 12, the statistical model shows the conceptual model is accurate at particle sizes smaller than the particle size corresponding to the critical settling velocity.

Table 7: Critical settling velocities and corresponding particle sizes Flow Particle diameter $(\mu \mathrm{m})$ Critical settling velocity $(\mathrm{m} / \mathrm{s})$

5 GPM

10 GPM

15 GPM
15

23

31
0.00021

0.00047

0.00084 

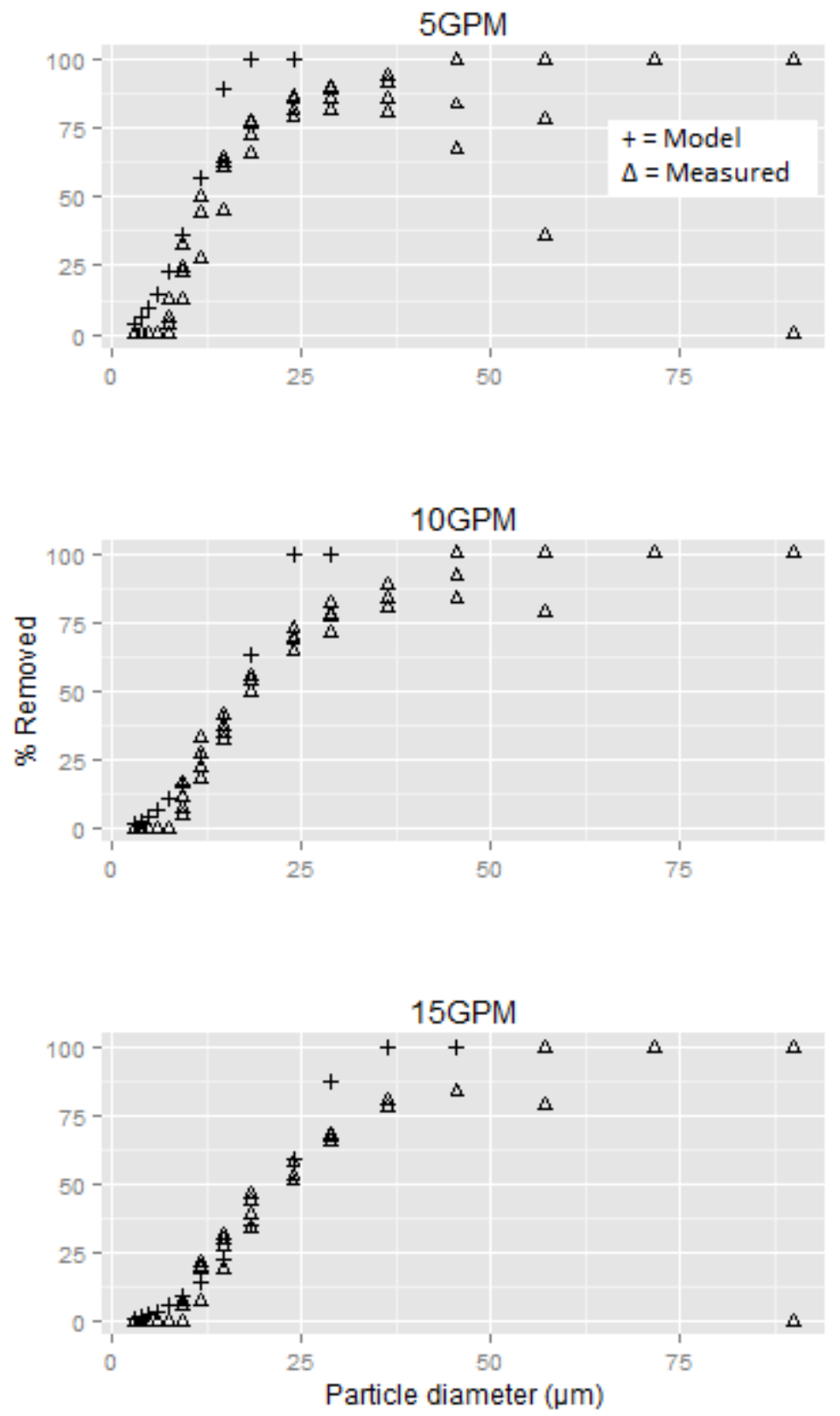

Figure 12: Conceptual and statistical models for removal fraction of particle sizes at 3 operational conditions 


\subsection{Statistical Model}

The particle sizing technique used allows for specification of 16 bin read sizes. Bin sizes selected can be seen in table X. Log10 interval spacing was used at the lower and upper bin limits as this spacing provided the most evenly distributed number of occurrences between bins when testing SCS. More evenly distributed occurrences between size ranges result in more accurate detection of changes in particle size. As mentioned, the particle sizing technique used is sensitive to concentration, and samples were stored for a number of months. As a result, small particles $2.59 \mu \mathrm{m}-9 \mu \mathrm{m}$ occasionally had higher counts in effluent samples than in influent samples, in which case it is assumed particles were not removed. Alternatively, higher counts of small particles could also have registered as effluent samples were not collected until a minimum of three cycle volumes of the MSR unit (approximately 100 gallons). It is possible flow conditions within the MSR unit caused small particle concentrations to fluctuate, or that the 50 lb SCS sample was not homogenous in particles smaller than $9 \mu \mathrm{m}$. Due to these occasional increases in small particle counts a model based on removal at specified bins is believed represent actual conditions more accurately than a model based on particle counts entering and exiting the device. 
Table 8: Selected size bins for particle counts used

\begin{tabular}{cc}
\multicolumn{2}{c}{ Particle Size $(\mu \mathrm{m})$} \\
\hline Lower size & Upper size \\
\hline 2.5 & 3 \\
\hline 3 & 3.76 \\
\hline 3.76 & 4.72 \\
\hline 4.72 & 5.92 \\
\hline 5.92 & 7.46 \\
\hline 7.46 & 9.32 \\
\hline 9.32 & 11.69 \\
\hline 11.69 & 14.67 \\
\hline 14.67 & 18.4 \\
\hline 18.4 & 23.9 \\
\hline 23.9 & 28.96 \\
\hline 28.96 & 36.34 \\
\hline 36.34 & 45.58 \\
\hline 45.58 & 57.19 \\
\hline 57.19 & 71.74 \\
\hline 71.74 & 90 \\
\hline 90 & + \\
\hline
\end{tabular}

Occurrences of removal percent observed across the 16 bin sizes can be seen in figure 13. A majority of the occurrences are $0 \%$ removal, followed by $100 \%$ removal. From figure 14 we can see that particles smaller than $10 \mu m$ account for almost $100 \%$ of the non-removals. It is assumed that non removal occurrences seen at the 90 micron size are due to either a number of small particles clumped into a larger particle in the effluent sample, or it could be to a particle counting error occurring. The count error is justified in that the difference proportion DP values presented in table 5 show the device makes less precise measurements at larger particle sizes. 

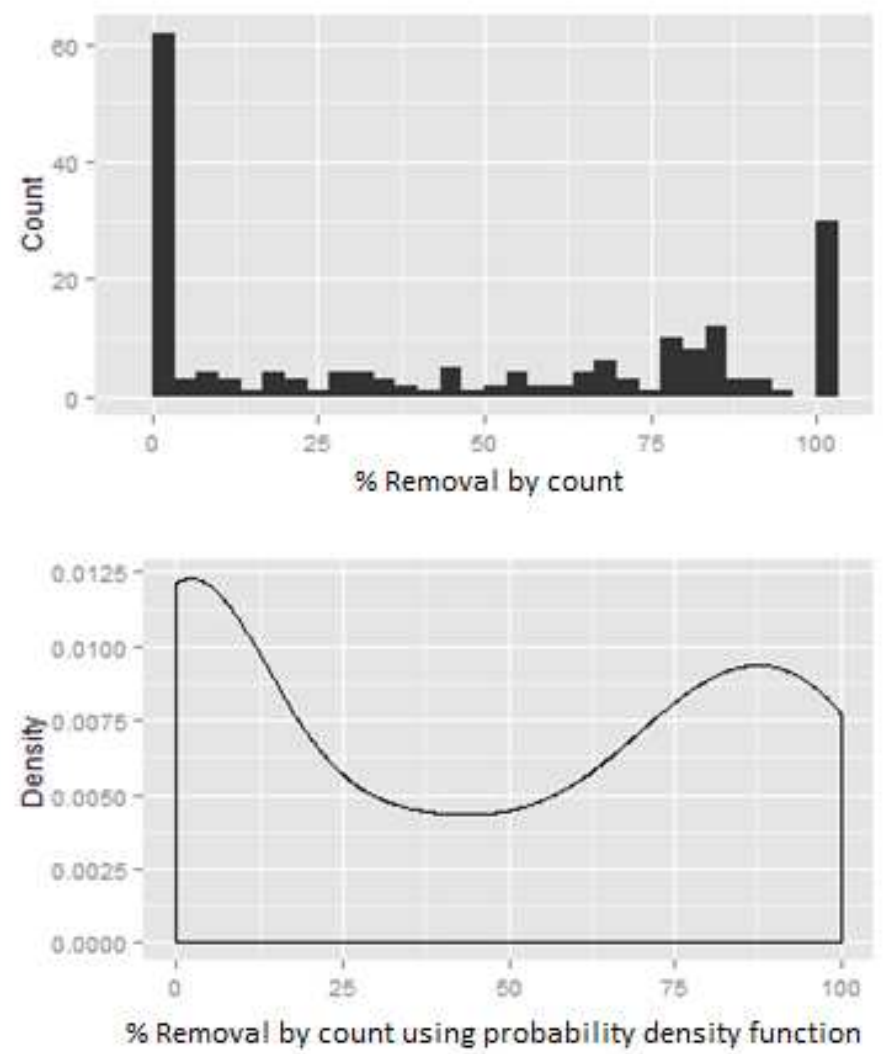

Figure 13: Occurrences of percent removal by count and corresponding density plot with particle measurements taken at log spacing intervals from $3.5 \mu \mathrm{m}$ to $90 \mu \mathrm{m}$ 


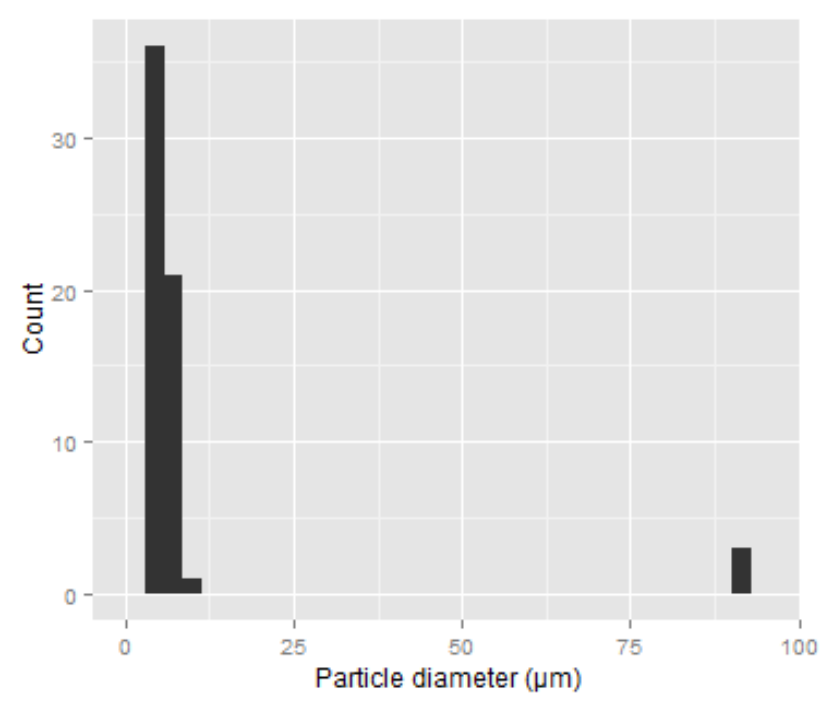

Figure 14: Occurrences of non-removal by particle diameter

\subsubsection{Selection of Statistical Model}

From density distribution seen in figure 13 it can be determined that a parametric model cannot be used to accurately represent removals observed at different bins as occurrences are not normally distributed. It has been shown that PSDs of stormwater solids can be made to be normally distributed using a log transform, however due to small particle counts fluctuating in this experiment, as previously mentioned modeling was based on removal of PSD rather than influent and effluent PSDs.

\subsubsection{Transformations}

A number of transformations can be applied to the removal data that will result in more normally distributed occurrences. Frequent occurrences of 0 prohibit inverse and log transforms. In a statistical analysis of rainfall data 
with 0 values Hndman and Gunwald (2000) used a two parameter version of the Box-Cox transform.

$$
g\left(y ; \lambda_{1}, \lambda_{2}\right)=\left\{\begin{array}{c}
\frac{\left(y+\lambda_{2}\right)^{\lambda_{1}}-1}{\lambda_{1}}, \text { when } \lambda_{1} \neq 0 \\
\log \left(y+\lambda_{2}\right), \text { when } \lambda_{1}=0
\end{array}\right. \text { (Equation 11) }
$$

Where $\lambda_{1}$ and $\lambda_{2}$ of the $\mathrm{BC}$ transform can be obtained using an algorithm or set to suggested literature values. Commonly values of 0 and 1 are used for $\lambda_{1}$ and $\lambda_{2}$ respectively. The BC transform would help in normalizing the data in that 0 occurrences could be eliminated, but the occurrences would then be skewed to the right and data would still not be normally distributed.

\subsubsection{Non-Parametric Regression}

Non-parametric regression is ideal in this situation as assumptions are not made regarding the particular probability distribution. The general nonparametric model is seen in equation 12 .

$$
Y=f\left(x_{1}, \ldots, x_{n}\right)+\varepsilon \text { (Equation 12) }
$$

In equation 12 a jointly conditional functional form is specified, meaning that interactions between independent variable $\mathrm{x}$ in its effects on $\mathrm{Y}$ are not constrained. According to (Jacoby n.d.) non-parametric models are best used when: there are no more than two predictors, the pattern of nonlinearity is complicated and when the sample size is sufficiently large. According to these 
criteria a non-parametric model is well suited for this data. The additive non-parametric regression model is seen in equation 13.

$$
\mathrm{Y}=\alpha+\sum_{\mathrm{j}=1}^{\mathrm{p}} \mathrm{f}_{\mathrm{j}}\left(\mathrm{x}_{\mathrm{j}}\right) \text { (Equation 13) }
$$

Where $\mathrm{f}_{\mathrm{j}}$ is a smooth function that is estimated by using a process of backfitting. Statistics software, such as $R$ has functions to determine f values at $\mathrm{x}$ so the model is easily applied to this dataset. Additive non-parametric regression was selected because the number of predictor variables is low, the pattern of non-linearity is complicated, and there was a significant amount of data collected. The generalized additive models package was used in $R$ to run the regression. A non-parametric model was also selected to predict sediment bound heavy metal concentrations based on particle size from experimental data, which is presented later. The concentrations of sediment bound metal displayed a high degree of non-linearity according to particle size and fit the other criteria for a non-parametric model as well.

\subsection{Model Output}

\subsubsection{Statistical Significance of Model}

As seen in table 8 both models $A$ and $B$ fit data well with adjusted $R$ square values of .867 and .874 respectively. We see that model B has a slightly higher degree of freedom however $\mathrm{P}$ values observed show correlation is 
statistically significant for both models and for all variables. It is believed that model B would better fit data if outliers observed at large particle sizes were accounted for.

Table 8: Statistical summary of models

\begin{tabular}{cccc} 
& Model A & \multicolumn{2}{c}{ Model B } \\
\cline { 2 - 4 } Variabe & Particle size & Flow rate & Particle size \\
\hline P-value & $<2 \mathrm{E}-16$ & 0.00132 & $<2 \mathrm{E}-16$ \\
\hline Degrees of Freedom & 8.4 & \multicolumn{2}{c}{8.5} \\
\hline Adjusted R-sq. & 0.867 & \multicolumn{2}{c}{0.874} \\
\hline Deviance explained & $87.2 \%$ & \multicolumn{2}{c}{$87.9 \%$} \\
\hline
\end{tabular}

Based on experimental results seen in figure 12 it is clear that particle size and flow rate can be used to predict removal. From the conceptual model and to a lesser extent, from experimental data, it is seen that particle size will affect removal more than flow rate. Model A predicts removal exclusively considering particle size while model B predicts removal considering both particle size and flow rate Parameters generated from model A may be seen in table 9 . 
Table 9: Parameters generated from non-parametric regression

\begin{tabular}{cc} 
Particle Size $(\mu \mathrm{m})$ & Modeled \% Removal \\
\hline 3 & 0 \\
\hline 3.76 & 0 \\
\hline 4.72 & 0 \\
\hline 5.92 & 2 \\
\hline 7.46 & 6 \\
\hline 9.32 & 13 \\
\hline 11.69 & 25 \\
\hline 14.67 & 40 \\
\hline 18.4 & 55 \\
\hline 23.9 & 68 \\
\hline 28.96 & 77 \\
\hline 36.34 & 84 \\
\hline 45.58 & 87 \\
\hline 57.19 & 86 \\
\hline 71.74 & 99 \\
\hline 90 & 100 \\
\hline
\end{tabular}

As seen by observing residuals in figure 15 the model tends to underestimate removal at the 5GPM and overestimate removal at 15GPM. At 10GPM residual location appears random. From residuals plot it is also seen that model could be fine-tuned. For the purpose of this research however the model is sufficient in that it is statistically significant and can therefore be used to demonstrate the applicability of the treatment practice based runoff approach. 


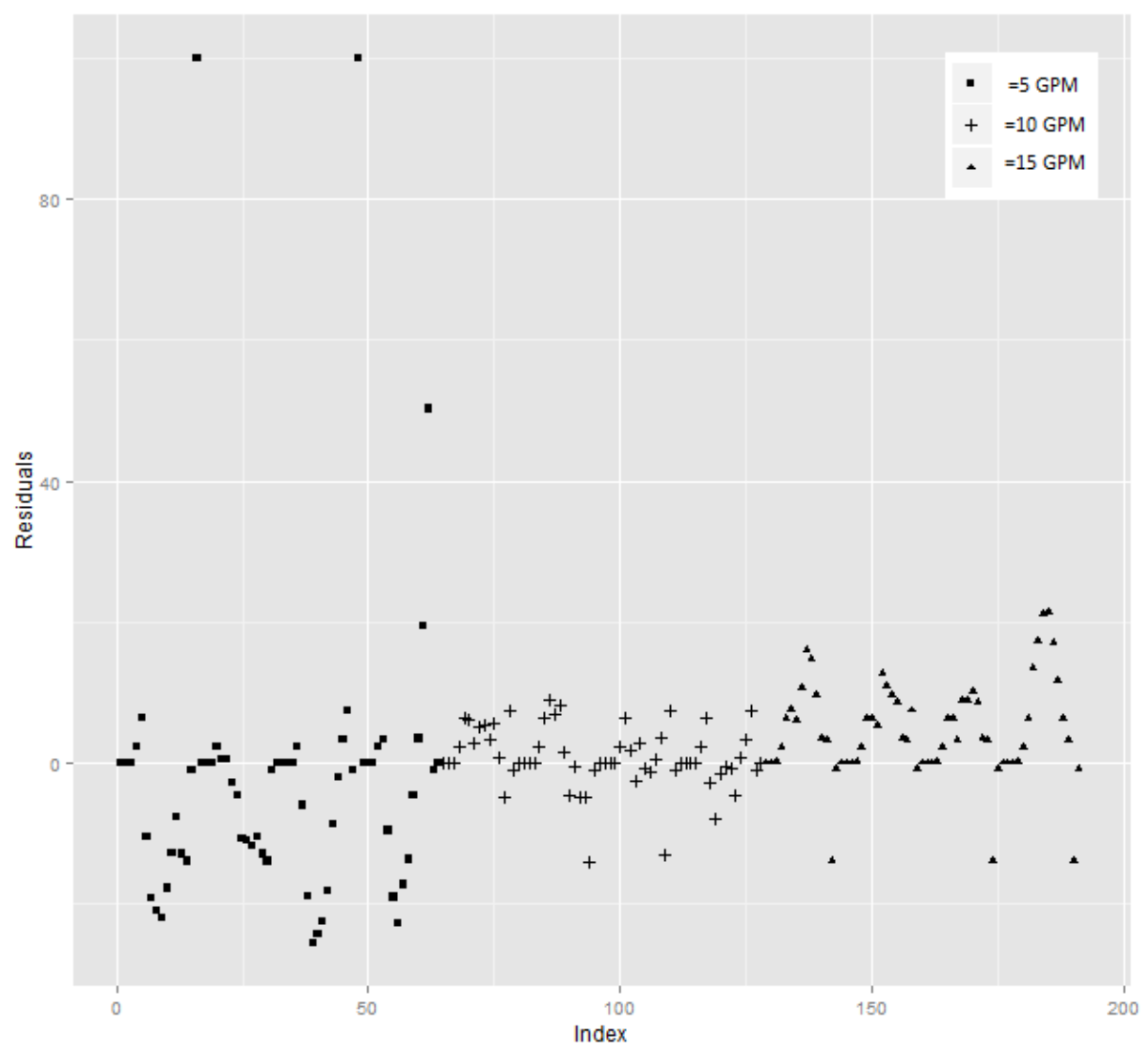

Figure 15: Residuals comparing model A to measured values

\subsubsection{Model Output Using PSD of Collected Stormwater Particulate}

It is seen in the statistical summary, in table 8, that particle size can be used alone to accurately predict effluent from the MSR device under normal flow conditions. If it is assumed stormwater BMPs operating with the same primary treatment process as the MSR unit are similarly dependent on particle size as an indicator of effluent quality, then it is apparent site specific PSDs should be considered when selecting a stormwater BMP. It is known that TSS and other water quality constituents vary for particular 
industries as evidenced by NPDES watershed based stormwater permitting system. The watershed based system allows businesses that consistently contribute more polluted stormwater runoff to surface waters to apply for permits with higher pollutant discharge benchmarks. As certain industries have higher pollutant runoff loads due to activities that take place in the drainage basin, it is logical that stormwater runoff pollutant loads will vary according to anthropogenic impacts, hydrologic factors and hydraulic factors. Efforts to determine runoff pollutant constituents should be approached on localized level to better account for variables that could affect TSS in runoff, and the PSD of the TSS. As mentioned particulate samples were collected from different locations in the City of Portland, and it was found that PSDs of those particulates varied. Captured solids collected do not necessarily correlate to PSDs of particulates in stormwater. However, due to the variability in visual appearance and differences in the PSD of collected particulate samples it is believed that stormwater runoff depositing collected solids is representative of the suspended solids transported during runoff.

Using the regression model developed for the MSR unit, and PSDs of particulate collected from different locations in the City of Portland, it is shown in table 10 that TSS removal of BMPs with a primary treatment process of sedimentation will depend on BMP location. Results are obtained 
exclusively considering particle size and it is assumed that particles have a constant specific gravity of 2.65 .

Table 10: Predicted mass reduction of particulate collected

$\begin{array}{ccc}\text { Sample site } & \text { Land use } & \text { Overall reduction \% } \\ 1 & \text { Residential } & 90.1 \\ 2 & \text { Commercial } & 81.9 \\ 3 & \text { Commercial } & 83.2 \\ 4 & \text { Residential } & 86.9 \\ 5 & \text { Industrial } & 87.9\end{array}$

According to the model, smaller particle size distributions measured at sites 2 and 3 , both high traffic commercial areas, would not be reduced as much as particles with larger size distributions seen in residential samples taken at sites 1 and 4 . This difference indicates that cities and towns complying with municipal separate storm sewer system (MS4) requirements would increase stormwater effluent quality by considering small scale watershed characteristics in the development of their stormwater management manuals (SWMM). At the least this model and collected data show justification for more extensive PSD testing of stormwater runoff in areas with different drainage basin characteristics. 
5.4 A Model to Predict Sediment Bound Heavy Metal Concentrations Based on PSD

In the case of agencies in charge of developing a SWMM, the utility of considering PSD in runoff is that the size and concentration of the particles can be correlated to effluent quality.

\subsubsection{Background}

Table 11, adapted from Wilson et al. (2007) shows heavy metal concentrations associated with particle sizes measured at different depositional locations using various collection methods. A trend showing an increase in concentrations associated with particle sizes as measured at different depositional locations using various collection methods. A trend showing in increase in particulate metal concentration with decreasing particle size is evident. Because smaller particles have a larger adsorptive specific surface area the observed trend is expected. However, it is important to keep in mind that particle metal concentrations depend on much more than just particle size.

Three retention processes factor into the amount of metal that will be bound to sediments which are: surface precipitation, fixation and sorbtion (Bradl 2004). In contaminated river sediments it has been shown that aqueous phase metal partitioning into particles is $\mathrm{pH}$ dependent (Soltan et al. 2006). An analytical procedure known as sequential extraction can be used to determine partitioning between particulate bound metals into: exchangeable, 
bound to carbonates, bound to Fe-Mn Oxides, bound to organic matter and residual fractions (Tessier et al. 1979). Results of a sequential extraction study of sediment cores taken from a heavily contaminated area of the EllRen River in Southern Taiwan are shown in Table 12. As seen the metals partition differently showing that elemental properties of the stormwater particle will affect the amount of a metal bound to a stormwater particle. Sequential extractions for metals in stormwater solids, along with PSD data, at a variety of different geographical locations and land use types would be useful in establishing more accurate estimates of particle bound metal concentrations.

Magill and Sansalone (2010) conducted a study measuring particle bound metal mass concentration as function of granulometry (size to surface area) in particles deposited in snow surrounding transportation corridors in the Lake Tahoe watershed. A gamma function was used to model cumulative mass metal distributions across PSDs for particulate deposited. The gamma model exceeded R squared values of .94 for all particle bound metal concentrations, demonstrating how site specific measurements considering particle size to surface area can accurately predict particle bound metal concentrations. The statistical model for particulate bound metals was combined with estimated BMP effluent solids characteristics by accounting for hydraulic and hydrologic variables. Similarly, this paper combines a 
statistical model with effluent solids particle size distribution to estimate the reduction of sediment bound metals. The Lake Tahoe study found that the majority of metal mass was bound to a median particle size ranging between (179 $\mu \mathrm{m}$ to $542 \mu \mathrm{m})$. These larger particles may be a concern in colder climates where snow surrounding transportation corridors is hauled to offsite storage areas where they accumulate, but the large median particle sizes reported for snow bound particles do not represent small particles of concern in stormwater as evidenced by regulatory specifications provided by the department of Ecology, (Howie et al. 2011) for size distributions of test solids used for certifying manufactured BMPs. 
Table 11:Particle bound heavy metal concentrations by particle size adapted from (Wilson et al. 2007)

\begin{tabular}{|c|c|c|c|c|c|}
\hline \multicolumn{4}{|c|}{ Metal Concentration (mg/kg) } & \multirow[b]{2}{*}{ Sediment Collection Location } & \multirow[b]{2}{*}{ Source } \\
\hline Particle Size Range $(\mu \mathrm{m})$ & $\mathrm{Cu}$ & $\mathrm{Pb}$ & $\mathrm{Zn}$ & & \\
\hline $1-43$ & 220 & 350 & 975 & \multirow{4}{*}{$\begin{array}{c}\text { Vacuumed streets in Los } \\
\text { Angeles }\end{array}$} & \multirow{4}{*}{$\begin{array}{c}\text { Lau and } \\
\text { Stenstrom, } \\
2005\end{array}$} \\
\hline $43-100$ & 235 & 300 & 800 & & \\
\hline $100-250$ & 235 & 210 & 500 & & \\
\hline $250-841$ & 240 & 45 & 150 & & \\
\hline $0.45-2$ & 2894 & 199 & 13540 & \multirow{5}{*}{$\begin{array}{l}\text { Stormwater outfall grab } \\
\text { samples in Tuscaloosa, Al }\end{array}$} & \multirow{5}{*}{ Pitt et al.,2004 } \\
\hline $2-10$ & 4668 & 868 & 13614 & & \\
\hline $10-45$ & 735 & 229 & 1559 & & \\
\hline $45-106$ & 1312 & 226 & 2076 & & \\
\hline $106-250$ & 2137 & 375 & 3486 & & \\
\hline $1-75$ & 465 & & 450 & \multirow{5}{*}{ Street sweepings in Sweden } & \multirow{5}{*}{$\begin{array}{c}\text { German and } \\
\text { Svensson,2002 }\end{array}$} \\
\hline $75-125$ & 285 & & 258 & & \\
\hline $125-250$ & 283 & & 202 & & \\
\hline $250-500$ & 170 & & 165 & & \\
\hline $500-1000$ & 50 & & 82 & & \\
\hline $1-50$ & 325 & 1600 & 4400 & \multirow{5}{*}{ Roadside Channels in France } & \multirow{5}{*}{$\begin{array}{c}\text { Rodger et al. } \\
1998\end{array}$} \\
\hline $50-100$ & 250 & 1450 & 1800 & & \\
\hline $100-200$ & 175 & 1500 & 1150 & & \\
\hline $200-500$ & 75 & 950 & 975 & & \\
\hline $500-1000$ & 75 & 500 & 975 & & \\
\hline $25-38$ & 347 & 238 & 1021 & \multirow{9}{*}{ Complete runoff deposits } & \multirow{9}{*}{$\begin{array}{c}\text { Sansalone and } \\
\text { Buchberger, } \\
1997\end{array}$} \\
\hline $38-45$ & 304 & 208 & 897 & & \\
\hline $45-63$ & 308 & 210 & 821 & & \\
\hline $63-75$ & 310 & 219 & 839 & & \\
\hline $75-150$ & 301 & 214 & 819 & & \\
\hline $150-250$ & 204 & 198 & 574 & & \\
\hline $250-425$ & 68 & 98 & 327 & & \\
\hline $425-850$ & 48 & 70 & 314 & & \\
\hline $850-2000$ & 45 & 37 & 266 & & \\
\hline
\end{tabular}

Table 12: Binding phases of particulate bound metals measured in sediment cores taken from the Ell-Ren River in Southern Taiwan adapted from (Yu et al. 2001)

\begin{tabular}{|c|c|c|c|c|}
\hline \multirow[b]{3}{*}{ Exchangeable } & $\mathrm{Cu}$ & $\mathrm{Pb}$ & $\mathrm{Zn}$ & $\mathrm{Cr}$ \\
\hline & \multicolumn{4}{|c|}{ Mean concentration $(\mathrm{mg} / \mathrm{kg})$} \\
\hline & 18.7 & 0.9 & 43.6 & 0.2 \\
\hline Bound to Carbonates & 21.5 & 34.6 & 184.5 & 4.5 \\
\hline Bound to Mn-oxides & Nondetectable & 1.9 & 30.9 & 0.2 \\
\hline Bound to Fe-oxides & 2.3 & 36.7 & 65.6 & 31.3 \\
\hline Bound to organic matter & 108.4 & 31.9 & 33.8 & 16.9 \\
\hline
\end{tabular}




\subsubsection{Statistical Summary of Particulate Bound Metals by Particle Size}

$\mathrm{R}$ squared values reported from the gamma model developed in the Lake

Tahoe watershed show that accurate estimates of particle bound metal concentrations can be made using site specific particle size to surface area measurements. As discussed many variables aside from size to surface area will determine the quantity of metal that will attach to a particle. However, in plotting log transforms of metal concentrations as reported in table 11 at particle sizes it is clear that particle bound metal concentrations show a trend of decreasing at increasing particle sizes. Additive non-parametric regression was used to establish a model estimating particulate bound metal as a function of particle size. As expected the general statistical models based exclusively on particle size are not as accurate as a site specific models considering particle size to surface area measurements. However, a statistically significant relationship between particle size and particulate metal can be made exclusively considering particle size, regardless of the fact that samples were collected from different geographic, land use and depositional environments. The fact that these models applied over a wide range of areas can explain between 29 and 49 percent of the deviance in concentration observed, and that site specific models can account for over 90 percent of deviance in particulate metal concentrations observed suggests that further studies considering particle size distributions of solids in 
stormwater due to anthropogenic, hydraulic and hydrologic factors would provide better predictive models of BMP effluent quality with respect to solids, and solids associated pollutants. Better predictive models of effluent quality would provide regulatory agencies in charge of developing SWMMs the ability to specify BMPs for a particular combination of anthropogenic, hydraulic and hydrologic conditions.

Table 13: Statistical summary for particulate metal concentration observed in stormwater particles at a variety of locations exclusively considering particle

\begin{tabular}{|c|c|c|c|}
\hline & $\begin{array}{l}\text { size } \\
\mathrm{Cu}\end{array}$ & $\mathrm{Pb}$ & $\mathrm{Zn}$ \\
\hline P-value & 0.0003 & 0.00978 & 0.00908 \\
\hline Degrees of Freedom & 11.02 & 8.11 & 5.38 \\
\hline Adjusted R-sq. & 0.46 & 0.25 & 0.32 \\
\hline Deviance explained & $49 \%$ & $29 \%$ & $37 \%$ \\
\hline
\end{tabular}



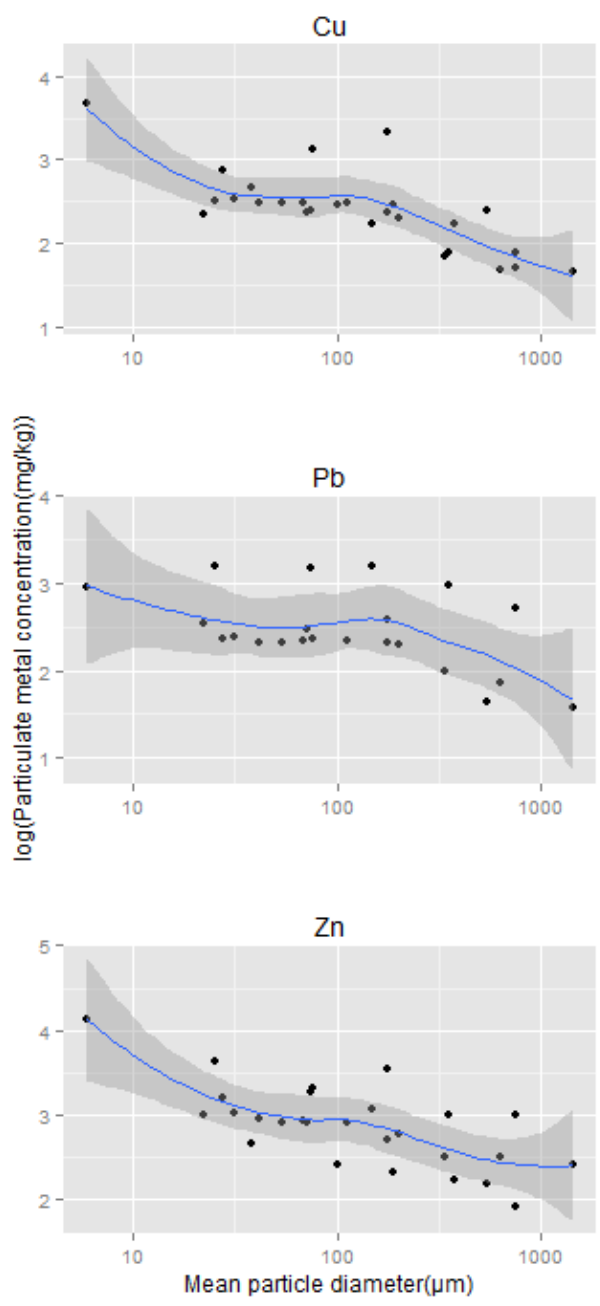

Figure 16: Particle bound copper, lead and zinc concentrations $(\mathrm{mg} / \mathrm{kg})$ by mean particle size based on data from table 9

\subsubsection{Using Particle Size and Associated Pollutant Concentrations to} Demonstrate Importance of Site Specific Runoff Characteristics To demonstrate how effluent quality for the same device changes depending on where it is located consider the statistical model developed relating particle size to attached metal concentration, the range of PSDs measured at different locations in the city, and how the influent solids PSD will determine effluent quality. 
First, the additive non-parametric model, shown in equation 14, used to predict the heavy metal concentrations for either $\mathrm{Cu}, \mathrm{Pb}$ or $\mathrm{Zn}$ at a particle size $\mathrm{x}$ can be applied. The estimated concentrations at particle sizes can then be combined with estimated equivalent spherical particle masses of influent at a specified influent concentration. For this demonstration SCS, and the PSD measured at the high traffic commercial area in SW Portland were used. The statistical model developed to estimate particle removal for the MSR unit based on particle size can then be applied. 

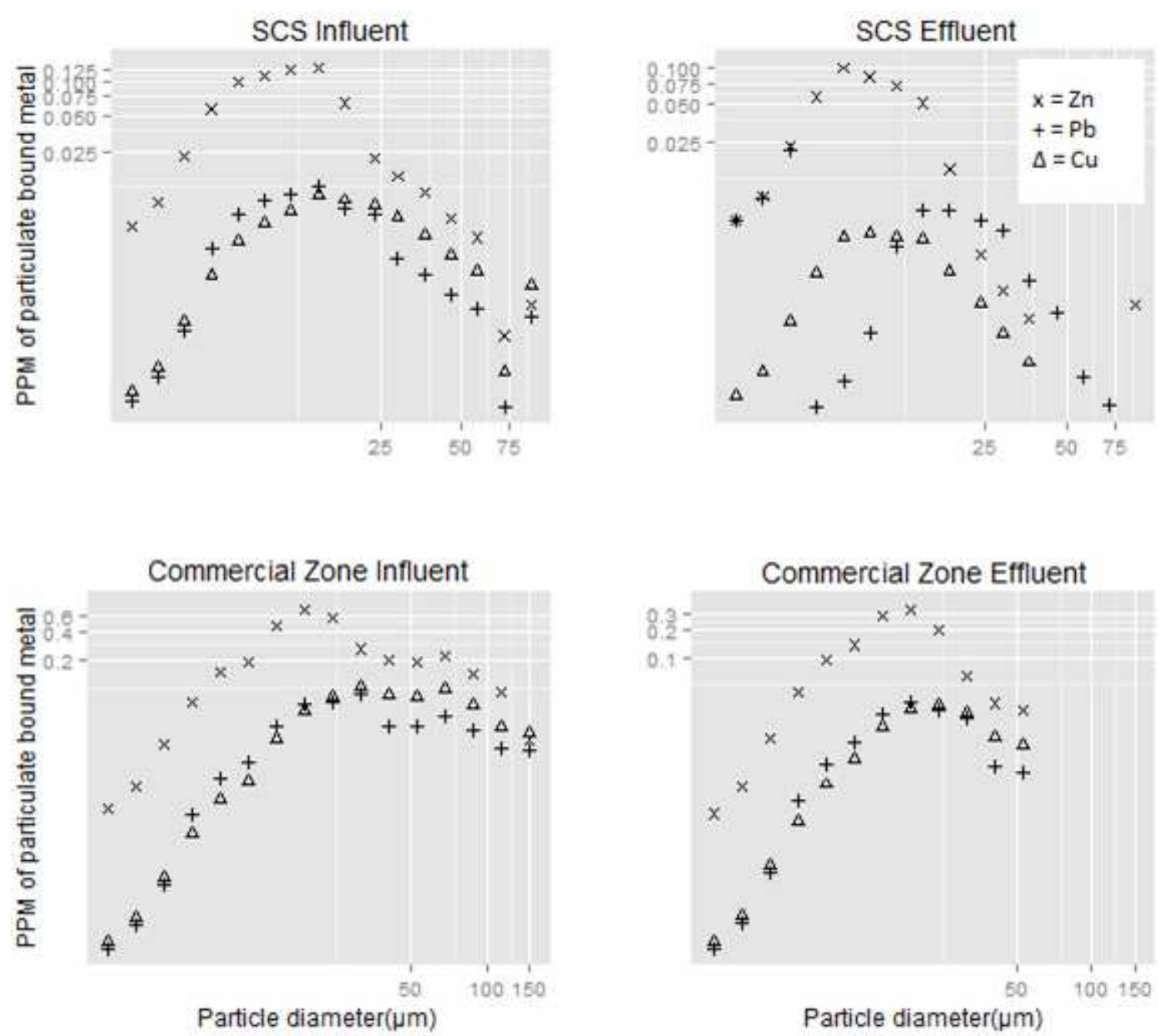

Figure 17: Estimated influent and effluent particulate bound $\mathrm{Zn}, \mathrm{Pb}$ and $\mathrm{Cu}$ for two different PSDs

Particle sizes of solids measured at the commercial zone in SW Portland, $\mathrm{d} 50 \approx 50 \mu \mathrm{m}$, are larger that SCS particles, $\mathrm{d} 50 \approx 19 \mu \mathrm{m}$, used to simulate storm events. Conceptually and empirically it has been shown, BMPs that use a primary treatment process of sedimentation remove larger particles more frequently than small particles. From the regression model overall reduction for commercial zone particles is estimated to be around $80 \%$, while the 
reduction of SCS would be around $50 \%$ under similar conditions. The influent concentration of the commercial zone is influent is higher, at approximately $200 \mathrm{mg} / \mathrm{L}$ vs. the $50 \mathrm{mg} / \mathrm{L}$ influent SCS concentration as studies reported by Strecker et al. (1997) show that TSS average in runoff is variable throughout Portland.

It could be hypothesized that because the smaller particles contain larger quantities of attached metals by mass, and are less likely to be removed by sedimentation that the SCS effluent would contain higher attached metal concentrations than the commercial zone effluent. Instead, it is seen in figure 17 that the effluent quality of larger size influent particles is higher in dissolved metal concentrations. Part of this result is due to differing influent solids concentrations; however particle volume, which is used to determine particle mass, increases as a cubic function of diameter, as such particles become heavier in an exponential manner with increasing size. On a mass to mass ratio the smaller particles contribute more particulate bound metal. Since the larger particles clearly contribute a greater portion of the overall mass they contribute more particulate bound metal in this case. This example illustrates how differing influent characteristics will affect effluent from the same BMP. Influent characteristics are likely to vary according to anthropogenic, hydraulic and hydrologic factors. Based on stormwater sediment samples collected at various geographic and land uses 
around Portland it is believed that PSDs of stormwater entering BMPs vary. As such BMPs with a primary treatment process of sedimentation will vary in performance. Stormwater discharge quality could be increased by accounting for factors that affect runoff in particular areas. Regulatory agencies responsible for NPDES MS4 permits, such as the City of Portland BES could incorporate these factors into their SWMMs so that more effective BMPs could be used for particular drainage basins or a set of conditions. 


\section{Chapter 6: Conclusion}

Human development changes the quantity of water a watershed infiltrates, as less water is infiltrated surface runoff increases and must be managed. Cities above a specified population that use an MS4 to manage stormwater, or a portion of it are required to comply with MS4 NPDES permits designed to reduce negative impacts to receiving bodies due to stormwater. MS4 NPDES permits cover entire municipalities and contain stipulations for dealing industrial/commercial facilities. These permits contain complex stormwater management plans for the areas or cities/towns within the specified municipality, and in the case of Portland, a stormwater management manual SWMM. The SWMM provides information on BMP selection, sizing and maintenance. This paper has shown that revisions to the SWMM to account for varying stormwater pollutant characteristics would allow the SWMM to provide better guidance on BMP selection, sizing and maintenance. The treatment practice based approach could be applied outside of Portland as well, however due to the large number of anthropogenic, hydraulic and hydrologic variables it is likely that localized studies will provide more accurate estimates.

Experiments and models presented herein provide evidence in favor of a treatment practice based approach. With this evidence a more detailed study on runoff characteristics, and particularly PSDs and particle densities of 
stormwater solids can be made with the intent of establishing statistically significant correlations between drainage basin characteristics and stormwater runoff.

\subsection{Ideas for Future Research}

An understanding of urban particles and associated pollutants, and how particles and associated pollutants correlate with different anthropogenic, hydraulic and hydrologic variables is necessary in order to specify treatment practices for a particular set of conditions. The correlation between particle bound metal concentration and particle size, developed in section 5.4.3., shows that further experiments on particle bound pollutant concentrations with respect to particle size, or surface area, would provide data that could be used in a statistical model to estimate of particle bound pollutant concentrations in stormwater runoff for a known PSD. Variables hypothesized to change particle bound pollutant concentration could be determined statistically. Likewise collecting more data on PSDs in stormwater runoff along with data on hypothesized variables could be used to provide statistical evidence for, or against, the treatment practice based concept of stormwater pollutant reduction.

Suspended solids size density determinations, meaning the densities of stormwater solids by size increment, and determining if size densities vary by location or some other hypothesized variable would provide information 
that could be used used to better predict solids removal of BMPs that use sedimentation; if statistically significant findings showing differing size densities correlated with hypothesized variables then this research could be incorporated into the treatment practice based concept. 


\section{Works Cited}

Bradl, H. B. (2004). "Adsorption of heavy metal ions on soils and soils constituents." Journal of Colloid and Interface Science, 277(1), 1-18.

Burian, S. J., and Edwards, F. G. (2004). "Historical Perspectives of Urban Drainage Steven.” Global Solutions for Urban Drainage, 1-16.

Frerichs, R. (n.d.). "Life and Times of Dr. John Snow." UCLA website, $<$ http://www.ph.ucla.edu/epi/snow.html\#FIRST DISCOVERED>.

German, J., and Svensson, G. (2002). "Metal Content and Particle Size Distribution of Street Sediments and Street Sweeping Waste." Water Science and Technology, 46(6-7), 191-8.

Gorski, J., and Fish, W. (2012). Removal of Total Suspended Solids in Stormwater using a Coalescing Plate Separator. Portland, Oregon, 12.

Grant, S. B., Rekhi, N. V, Pise, N. R., Reeves, R. L., Matsumoto, M., and Wistrom, A. (2003). A Review of the Contaminants and Toxicity Associated with Particles in Stormwater Runoff.

Hargesheimer, E. E., and Lewis, C. (n.d.). Particle Counting: How, Why, Where, \& What Equipment. 1-18.

Hndman, R., and Gunwald. (2000). "Generalized Addivitve Modeling of Mixed Distribution Markov Models With Application To Melornes 's Rainfall." $42(2), 145-158$.

Howie, D., Joel, B., Marx, K., James, A., Lenth, J., Ahearn, D., and Zisette, R. (2011). Technical Guidance Manual for Evaluating Emerging Stormwater Treatment Technologies Technology Assessment Protocol.

Isfahani, Z. K. (2013). "Statistical Analysis of Stormwater Device Testing Protocols in Portland, Oregon by Zahra Kavianpour Isfahani."

Jacoby, B. (n.d.). "Regression III : Advanced Methods." $<$ http://polisci.msu.edu/jacoby/icpsr/regress3/lectures/week4/15.Loess.pdf $>$ (May. 6, 2013).

Lau, S, and Stenstrom, M.K. (2005). "Metals and PAHs adsorbed to street particles." Water Research, PubMed Database. 
Leisenring, M., Clary, J., and Hobson, P. (2012a). "International Stormwater Best Management Practices ( BMP) Database Pollutant Category Summary Statistical Addendum: TSS , Bacteria , Nutrients, and Metals July 2012." (July), 1-31.

Leisenring, M., Clary, J., and Hobson, P. (2012b). "International Stormwater Best Management Practices ( BMP) Database Manufactured Devices Performance Summary July 2012.” (July), 1-18.

Leisenring, M., Clary, J., Lawler, K., and Hobson, P. (2011). International Stormwater Best Management Practices (BMP) Database Pollutant Category Summary: Solids (TSS , TDS and Turbidity). 1-28.

Li, Y., Lau, Sim-lin, Kayhanian, M., Asce, M., Stenstrom, Michael K, and Asce, F. (2005). "Particle Size Distribution in Highway Runoff." (September), 1267-1276.

Magill, N., and Sansalone, J. (2010). "Distribution of Particulate-Bound Metals for Source Area Snow in the Lake Tahoe Watershed." Journal of Environmental Engineering, (February), 185-193.

Pitt, R., Clark, P. D., Johnson, R., Morquecho, S., and Pratap, M. (2004). High Level Treatment of Stormwater Heavy Metals. Salt Lake City, 917-926.

Rees, R. (1996). "Under the Weather Climate and Disease, 1700-1900." History Today, 35-41.

Roger, S., Montrejaud-Vignoles, M., Andral, M. ., Herremans, L., and Fortune, J. . (1998). "Mineral, Physical and Chemical Analysis of the Solid Matter Carried by Motorway Runoff Water." Water Research, 32(4), $1119-1125$.

Schwarz, T. S. (1999). "Stormwater Particle Removal Using a Cross-Flow Filtration and Sedimentation Device." Portland State University.

Schwarz, T., and Wells, S. (1999). "Storm Water Particle Removal using Cross-Flow Filtration and Sedimentation." Advances in Filtration and Separation Techonlogy, 12, 219-226.

Seeger, H. (1999). "The history of German waste water treatment." European Water Management, 2(5), 51-56. 
Soltan, M. E., Rashed, M. N., and Taha, G. M. (2006). "Heavy Metal Levels and Adsorption Capacity of Nile River Sediments." International Journal of Environmental Chemistry, (June 2013), 37-41.

Strecker, E. W., Binhong, W., and Iannelli Michael. (1997). Analysis of Oregon Urban Runoff Water Quality Monitoring Data Collected from 1990 to 1996. Portland, Oregon.

Takamatsu, M., Barrett, M., and Charbeneau, R. J. (2010). "Hydraulic Model for Sedimentation in Storm-Water Detention Basins." Journal of Environmental Engineering, 136(5), 527-534.

Tessier, a., Campbell, P. G. C., and Bisson, M. (1979). "Sequential Extraction Procedure for the Speciation of Particulate Trace Metals." Analytical Chemistry, 51(7), 844-851.

The United States Environmental Protection Agency, (EPA). (2005). Stormwater Phase II Final Rule An Overview. 1-4.

The United States Environmental Protection Agency, E. (1971). Residue, Non-Filterable (Gravimetri, Dried at 103-105C). 3.

Washington Department of Ecology. (2004). Guidance for Evaluating Emerging Stormwater Treatment Technologies Technology Assessment Protocol - Ecology.

Wilson, M. A., Gulliver, J. S., Mohseni, O., Hozalski, R. M., Road, L., Cities, T., and Council, M. (2007). Performance Assessment of Underground Stormwater Treatment Devices.

Wright, B. K. R., Zegarra, A. V., and Lorah, W. L. (1999). "Ancient Machu Picchu Drainage Engineering." Journal of Irrigation and Drainage Engineering, (December), 360-369.

Yu, K., Tsai, L., and Chen, S. (2001). "Multvariate Correlations of Geochemical Binding Phases of Heavy Metals in Contaminated River Sediment." Journal of Environmental Science and Health, (July 2013), $37-41$. 